Universidad de Lima

Facultad de Ciencias Empresariales y Económicas

Carrera de Contabilidad

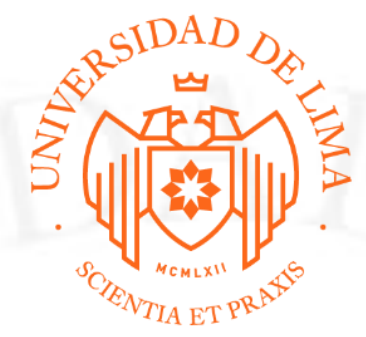

\title{
ANÁLISIS FINANCIERO DE LA EMPRESA FILAMENTOS INDUSTRIALES S.A.
}

Trabajo de suficiencia profesional para optar el Título Profesional de Contador Público

\section{Jeni Alicia Mego Quiquia}

Código 20042320

\section{Asesor}

Ahmed Vega Cruces

Lima - Perú

Octubre de 2018 


\section{FINANCIAL ANALYSYS OF THE COMPANY FILAMENTOS INDUSTRIALES S.A.}




\section{DEDICATORIA:}

El presente trabajo de suficiencia profesional está dedicado a las tres personas más importantes de mi vida, que estuvieron siempre a mi lado apoyándome y dando lo mejor de sí, para que siga creciendo como persona y profesionalmente, a mi madre Mery, a mi segunda madre mi abuela Rosa que desde el cielo ambas cuidan mi camino y a mi esposo Gian Carlo gracias por tus consejos, por tu comprensión y por todo tu apoyo en los momentos difíciles que me toco pasar. 


\section{TABLA DE CONTENIDO}

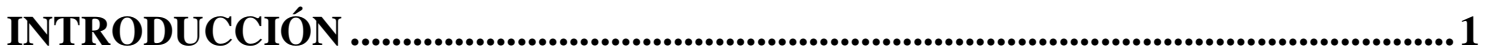

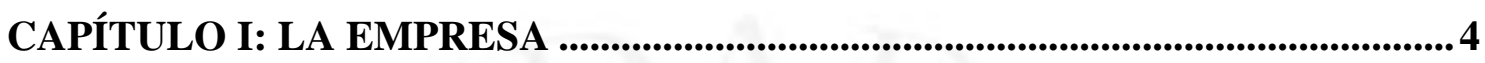

1.1 Antecedentes, identificación y actividad económica de la entidad .................4

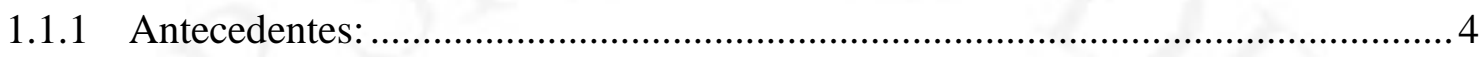

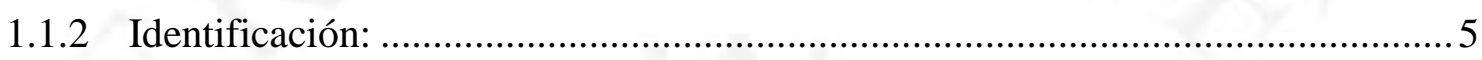

1.1.3 Actividad Económica: ......................................................................... 6

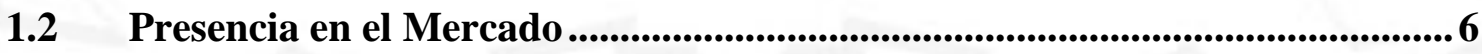

CAPÍTULO II: DESCRIPCIÓN Y OBJETIVOS DEL TRABAJO DE

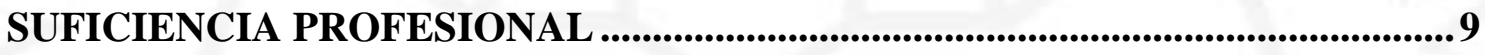

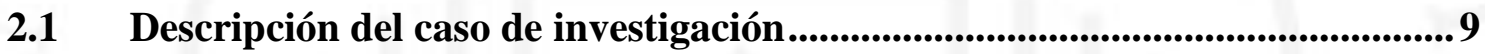

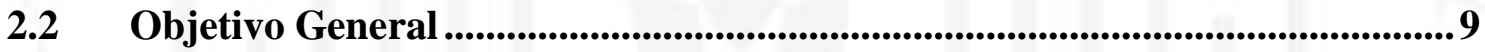

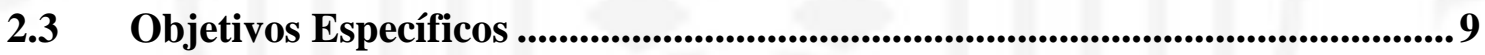

CAPÍTULO III: MARCO METODOLÓGICO .......................................................... 10

3.1 Metodología de recolección de la información ...............................................10

3.2 Metodología de análisis de la información................................................10

CAPÍTULO IV: ANÁLISIS, PRESENTACIÓN Y DISCUSIÓN DE

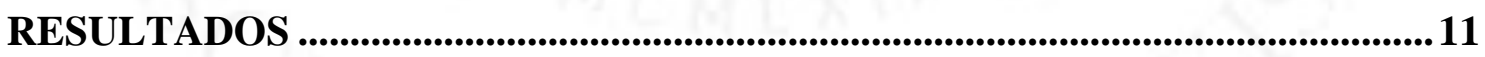

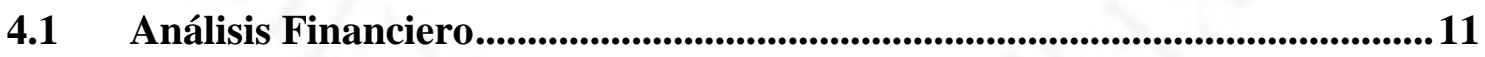

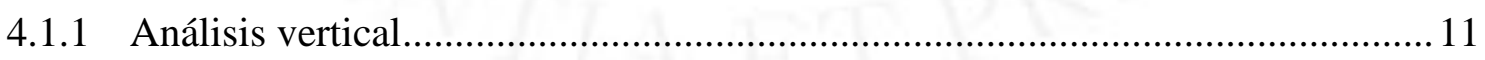

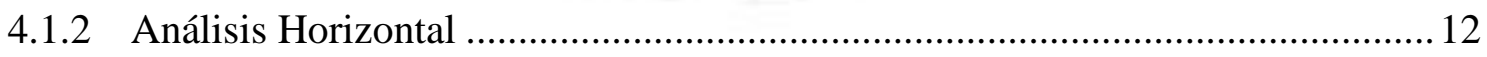

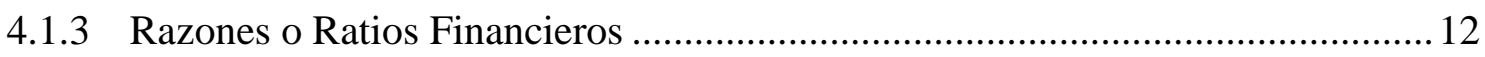

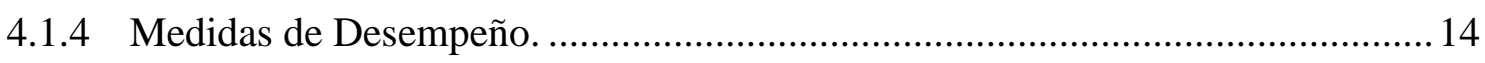

4.2 Presentación y discusión de Resultados .....................................................15 


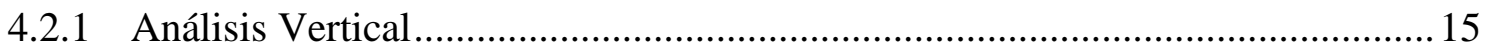

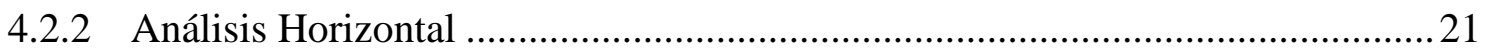

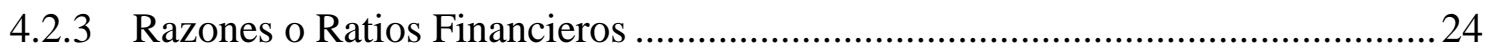

4.3 Proyección del Estado de Situación Financiera ......................................................31

4.4 Proyección del Estado de Resultados Integrales ............................................33

4.5 Análisis de información financiera de acuerdo a NIIF...............................34

4.5.1 NIIF 9 Instrumentos Financieros: presentación sobre la clasificación, medición y reconocimiento de los activos y pasivos financieros ............................................ 34

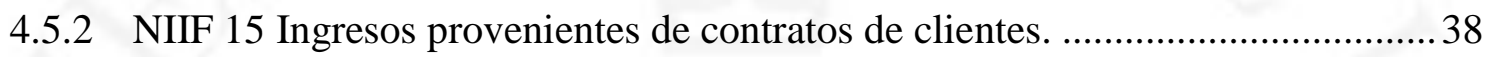

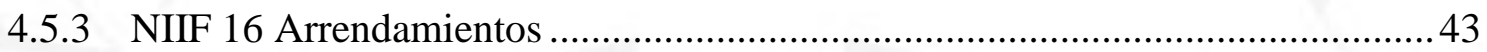

4.6 Aspectos Relevantes de la Reforma Tributaria...............................................45

4.6.1 Decreto Legislativo $\mathrm{N}^{\circ} 1369$ que modifica la Ley del Impuesto a la Renta........ 45

4.6.2 Decreto Legislativo $\mathrm{N}^{\circ} 1422$ que modifica el Código Tributario.........................47

4.6.3 Decreto Legislativo $\mathrm{N}^{\circ} 1424$ que modifica la Ley del Impuesto a la Renta........ 47

4.6.4 Decreto Legislativo $\mathrm{N}^{\circ} 1425$ que modifica la Ley del Impuesto a la Renta........48

CAPÍTULO V: CONCLUSIONES Y RECOMENDACIONES ................................49

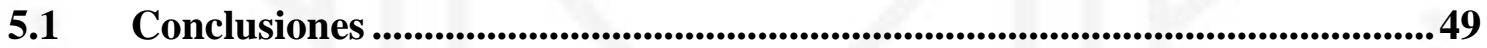

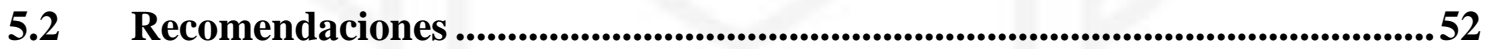

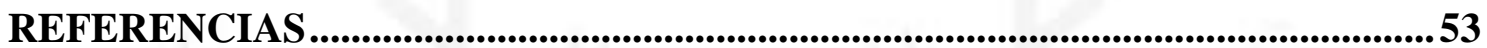

BIBLIOGRAFÍA …....................................................................................................554 


\section{ÍNDICE DE FIGURAS}

Figura 1 Venta de Hilado de Polyester y Nylon al 2014 .......................................... 1

Figura 2 Venta de Hilado de Polyester y Nylon al 2017 ...........................................2

Figura 1.1 Hilo de Polyester y Nylon ............................................................... 7

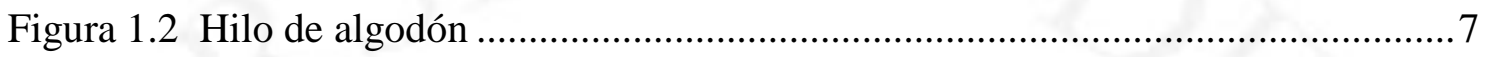

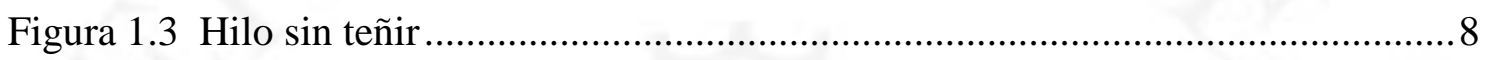

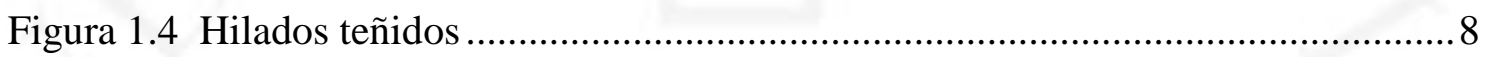




\section{ÍNDICE DE TABLAS}

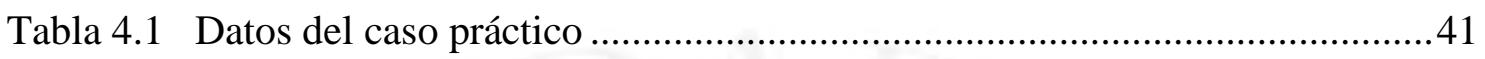

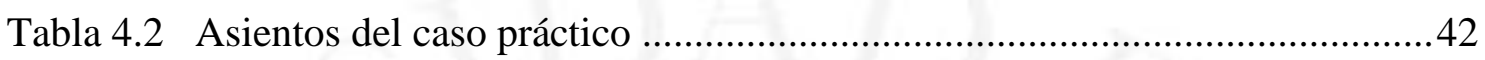




\section{ÍNDICE DE ANEXOS}

Anexo 1: Análisis Vertical del Estado de Situación Financiera ................................... 17

Anexo 2: Análisis vertical del Estado de Resultados Integrales ...................................20

Anexo 3: Análisis Horizontal del Estado de Situación Financiera .................................22

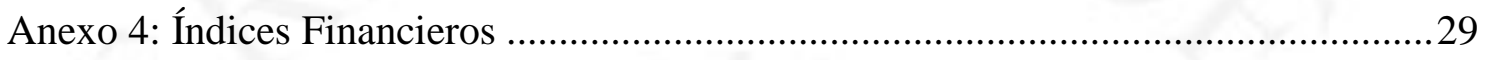

Anexo 5: Proyección del Estado de Situación Financiera Periodos 2018 al 2022 ..........31

Anexo 6: Proyección del Estado Resultados Integrales para los Periodos 2018 al 2022. 


\section{INTRODUCCIÓN}

El presente trabajo de suficiencia profesional consiste en la elaboración del análisis financiero de la empresa Filamentos Industriales S.A. (en adelante la empresa). La empresa se constituyó el 03 de julio de 1974 en la ciudad de Lima, dedicándose a la fabricación de hilados de polyester texturizado hasta el mes de junio del año 2014. Durante los años 2012 y 2013 obtuvo el 45\% y 32\% de participación en el mercado de producción nacional de hilado de polyester teniendo como principal competidor al hilo importado.

La empresa había designado el $92.48 \%$ de su producción del hilado polyester y nylon a la venta en el mercado interno y lo que restaba de su producción el 7.52\% estaba destinado a la venta en el mercado extranjero. En la figura 1 se muestra la cantidad vendida en toneladas por año del hilado polyester y nylon tomando como base los periodos 2010 al 2014.

Figura 1

Venta de Hilado de Polyester y Nylon al 2014

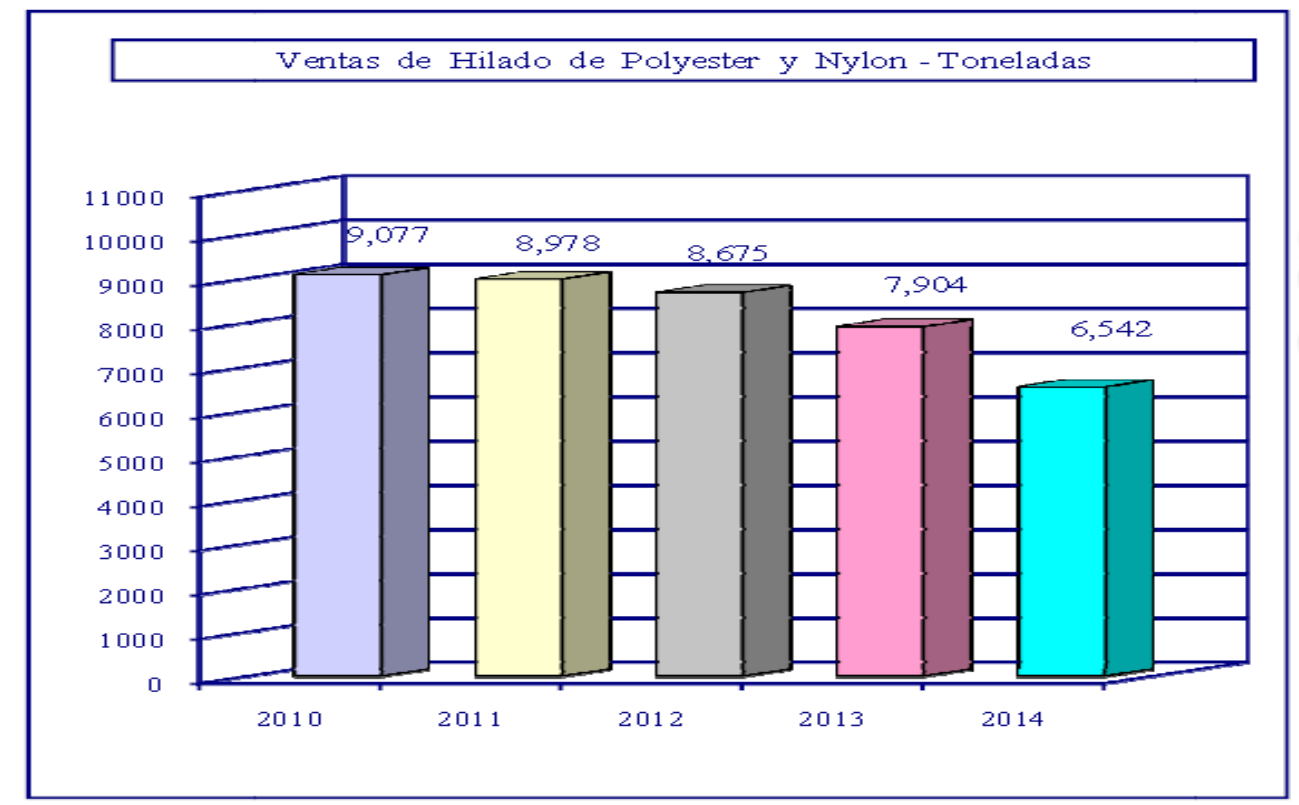

Fuente: Memoria Anual Fisa 2014 
En tal sentido, se puede apreciar que las ventas de hilado de polyester y nylon en toneladas van disminuyendo año tras año empezando a caer desde el año 2011 hasta el 2014, pasando de 9,077 T.M. a terminar en 6,542 T.M. En el año 2013 la empresa identifica indicios de deterioro en las maquinarias y equipos de producción del hilado polyester basados en la baja demanda de los productos de mayor aporte de ingresos a la empresa, debido a la fuerte competencia de precios por la excesiva importación de hilos y telas que vienen desde la China, Indonesia y Malasia. Para afrontar esta competencia de hilos importados a precios bajos, la empresa a mediados de junio del año 2014, toma la decisión de cerrar su planta de producción y sustituirla por la importación y posterior comercialización del hilado polyester, permitiéndole a la empresa a competir en el mercado nacional con precios bajos y con productos de calidad similar a las que venía produciendo.

A continuación, se puede apreciar en la figura 2 que las ventas de hilado de polyester y nylon en toneladas para los periodos 2016 al 2017 se va incrementando pasando de 7,628 TM a 8,147 T.M. teniendo como producto principal el hilado de filamento polyester.

Figura 2

Venta de Hilado de Polyester y Nylon al 2017

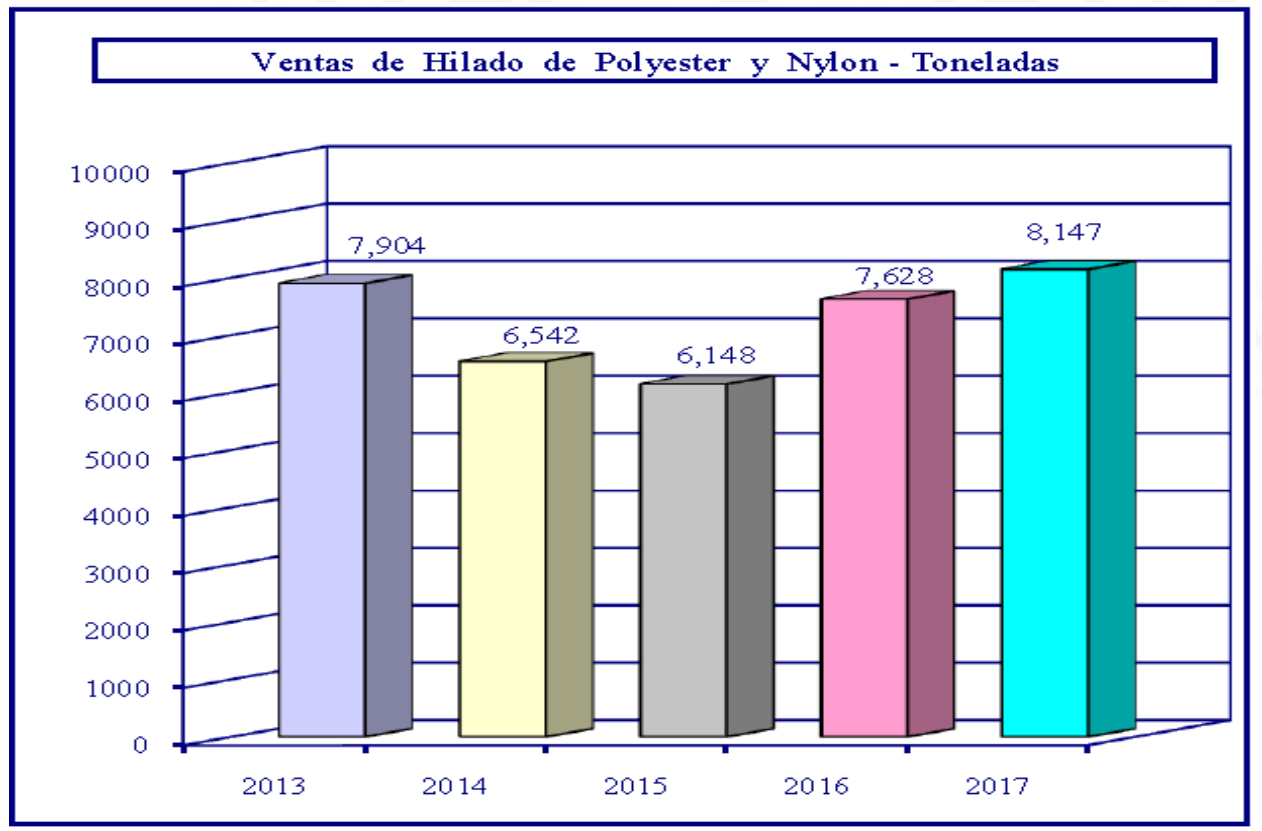

Fuente: Memoria Anual Fisa 2017 
Debido a ello, al tomar conocimiento de la intención de crecimiento de la empresa se considera importante la elaboración de un análisis financiero de los periodos cerrados de los años 2011 al 2017; utilizando como base para el análisis los estados financieros de dichos periodos, el objetivo principal es de presentar un análisis general de la situación financiera y económica de Filamentos Industriales S.A.; para ello utilizaremos los métodos o técnicas para la interpretación de la situación financiera y económica de la empresa; las técnicas a utilizar son: Análisis Vertical, Análisis Horizontal y Razones o Ratios Financieros.

Posteriormente, de realizarse la evaluación financiera y económica de la empresa se realizará una proyección con un horizonte de 5 años, para evaluar el comportamiento del crecimiento de la empresa con los cambios introducidos en su plan de adecuación denominado FISA 2014.

Finalmente se presentará las conclusiones y recomendaciones para la empresa. 


\section{CAPÍTULO I: LA EMPRESA}

\subsection{Antecedentes, identificación y actividad económica de la entidad}

\subsubsection{Antecedentes:}

La empresa inicia sus actividades en la ciudad de Lima en el año 1974, en la memoria anual de (FISA, Memoria Anual, 2011), precisa lo siguiente:

La empresa se fundó en el año 1974, iniciando sus actividades fabriles con una capacidad instalada de 1.50 T.M. de producción mensual de hilados de polyester texturizado. En la década del ochenta, con la apertura económica, implementamos nuevas maquinarias y equipos para elevar la capacidad instalada de producción a 580 T.M. mensuales; la que fue aumentada a 800 T.M. mensuales, con una inversión de US\$ 4.5 millones durante los años 2001 a 2007, logrando también mejorar en la tecnología de producción de hilado polyester. (p.6)

Durante los años 2011 al 2012 la empresa obtuvo el 45\% de participación en el mercado de producción nacional de hilado polyester, para el año 2013 se posiciono en $32 \%$. En ese mismo año la empresa decide realizar una evaluación de sus activos fijos identificando indicios por deterioro en sus maquinarias y equipos de producción, originando una evaluación y posterior provisión por deterioro de activos fijos por el importe de S/ 34, 972 de acuerdo a lo establecido por la NIC 36 (Deterioro del valor de los activos). Para el año 2014 la empresa evalúo los resultados y las proyecciones del primer trimestre con respecto a la venta en el mercado del hilo polyester de producción local, la Gerencia General toma la decisión de cerrar su actividad de producción en base a los resultados obtenidos, debido a la baja demanda de sus productos de mayor circulación que aportan el $92.48 \%$ de ingresos a la empresa, emitiendo así en el mes de junio de ese mismo año un plan de adecuación para adaptarse a la actual situación de mercado. 
De lo mencionado en el punto anterior, la empresa desarrolla los lineamientos sobre la decisión de cerrar su actividad de producción, de acuerdo a lo establecido en la Memoria Anual de (FISA, Memoria Anual, 2014):

Para afrontar la fuerte competencia de los hilados importados (principalmente de la india) a precios que no nos permiten competir con producción nacional, así como el incremento año tras año de los costos de producción por factores ajenos a la empresa, resulta clara la necesidad de sustituir paulatinamente, pero en el menor tiempo posible, la producción local (que se mantendrá únicamente hasta que se consuma el stock actual de materia prima de chips polyester), por la importación creciente de hilado de acuerdo a las necesidades del mercado local. (p.8)

En base a lo señalado a mediados del año 2014, la empresa toma la decisión de sustituir su producción del hilado polyester por la importación de productos similares permitiéndole competir en el mercado nacional con precios bajos y productos de calidad similar de las que venía produciendo con el objetivo de mejorar su participación de mercado e incrementar la utilidad operativa.

\subsubsection{Identificación:}

El capital social suscrito y pagado por la empresa equivale a S/ 23 502,270 con un valor nominal de S/1.00 por acción. Esta información lo podemos encontrar en la memoria anual de (FISA, Memoria Anual, 2017) que dispone lo siguiente:

El capital social de la compañía suscrito y pagado al 31.12.2017 es por S/ 23 502,270; con un total de número de acciones comunes 23 502,270 a un valor nominal por acción de S/ 1.00. Las acciones de circulación son por S/ 11 751,082 con un valor nominal por acción de S/1.00. Entre los principales accionistas tenemos: Gladys Simón Jamis Viuda de Musiris con el 46.62\% de participación, le sigue el Sr. Antonio Musiris Simón con el 23.05\% de participación; seguido de Gladys Malule Musiris Simón con el 15.17\% participación y Melissa Anna Musiris Simón con el 15.17\% de participación. (pp.8-9)

Filamentos Industriales S.A. tiene registrado como domicilio fiscal ante Administración Tributaria - SUNAT a la Av. Manuel Olguín N³53, oficina 1501, 
urbanización Los Granados distrito de Santiago de Surco, Lima; y como establecimiento anexo a Jr. Los Hornos $N^{\circ} 353$, Urbanización Infanta, Los Olivos Lima.

\subsubsection{Actividad Económica:}

A partir del año 2014 la empresa cambio su objeto social paso de fabricación de filamentos texturizados de fibra sintética a actividades de importación tal como está señalado en objeto social de la memoria anual de (FISA, Memoria Anual, 2017):

La empresa tiene por objeto dedicarse a las actividades de importación, comercialización, exportación, distribución, intermediación al por mayor y/o al menudeo de bienes de y para industria textil a nivel nacional e internacional, pudiendo dedicarse a otras actividades afines, conexas y/o complementarias a la actividad empresarial. Asimismo, la empresa podrá dedicarse a actividades inmobiliarias relacionadas con la construcción, adquisición, compra, venta y, en general transferencia de bienes, así como su administración en cualquiera de sus actividades y modalidades. Podrá arrendar activa o pasivamente bienes muebles e inmuebles; permutar, hipotecar los bienes de los inmuebles de la Sociedad y determinar la aplicación o inversión de los recursos de la empresa. Así mismo, la Sociedad podrá constituir, adquirir o integrar de manera directa o con terceros, otras personas jurídicas, sean sociedades, instituciones, corporaciones o asociaciones de cualquier de cualquier clase o naturaleza en el Perú y en el extranjero. (p.7)

\subsection{Presencia en el Mercado}

La actividad económica actual de la empresa, es la comercialización de productos textiles, principalmente de filamentos texturizados de polyester, destinados a la industria textil.

Dentro de los diferentes productos y servicios que ofrece la empresa tiene el Hilo de Polyester, Nylon, Viscosa, Algodón, Polyalgodón, Hilos Brillantes, Polyester Teñido dentro del tipo de servicio que desarrolla la empresa tenemos el teñido de Hilo, Servicio Técnico y Servicio de Laboratorio. 
- Hilo de Polyester y de Nylon: es utilizado para la fabricación de medias, ropa interior, guantes, toallas, vestidos, corbatas y pantalones.

Figura 3.1

Hilo de Polyester y Nylon

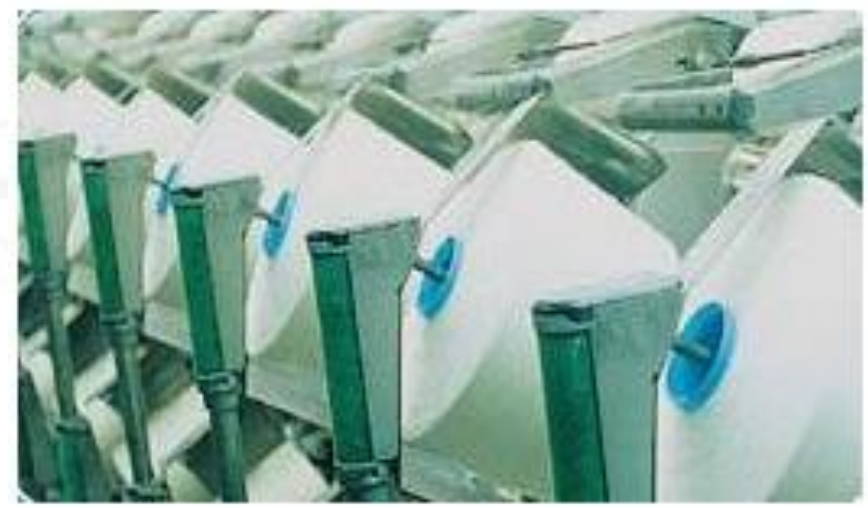

- Hilo de algodón: es utilizado para la fabricación y

- confección de polos, medias, chompas, faldas, blusas etc., también es utilizado para la fabricación de alfombras y cortinas.

Figura 3.2

Hilo de algodón

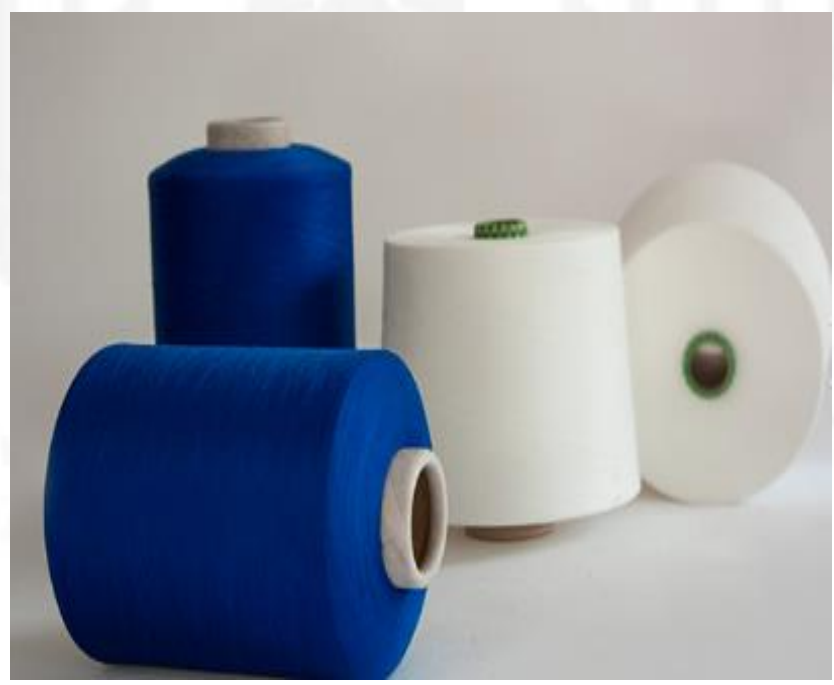

- Hilados sin teñir: este producto es utilizado para la fabricación telas sólidas un solo color en tejidos como el Jersey, Rib, Gamuza, Franela, Interlock, etc. 
Figura 3.3

Hilo sin teñir

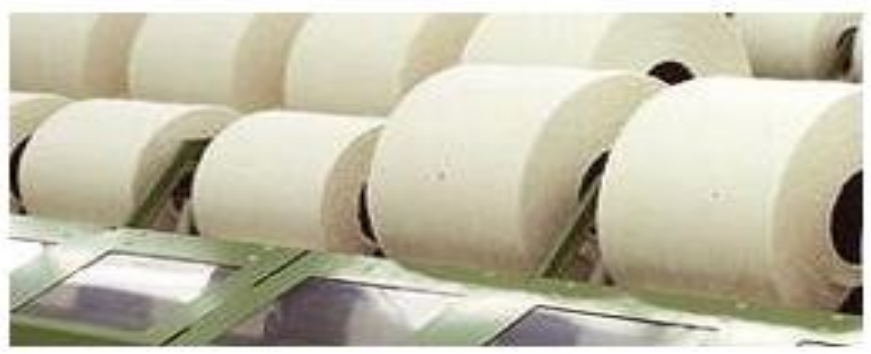

- Hilados Teñidos: este hilado es utilizado para la producción de telas listadas (rayadas) es combinado con diferentes colores y diseños, en tejidos como el Jersey, Rib ${ }^{1}$, Gamuza, Franela, Interlock ${ }^{2}$ etc.

Figura 3.4

Hilados teñidos

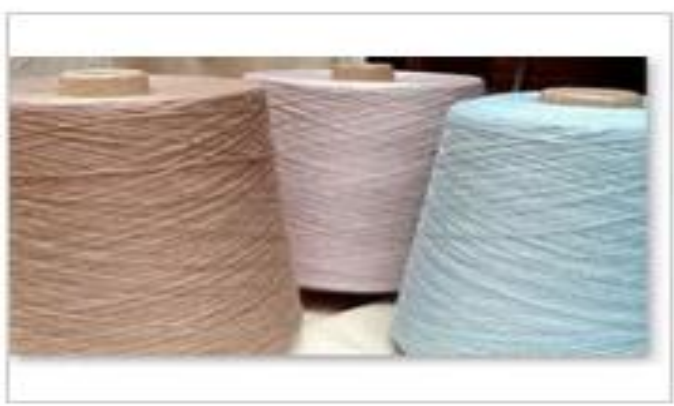

\footnotetext{
${ }^{1}$ La Tela Rib algodón o resorte en algodón es un textil suave, elástico y con una superficie acanalada la cual es perfecta para la confección de cuellos, puños y cinturas de sudaderas de todo tipo.

${ }^{2}$ Tejido de Jersey pesado, utilizado para camisetas.
} 


\section{CAPÍTULO II: DESCRIPCIÓN Y OBJETIVOS DEL TRABAJO DE SUFICIENCIA PROFESIONAL}

\subsection{Descripción del caso de investigación}

En el presente trabajo se presentará un análisis general de la situación financiera y económica de Filamentos Industriales S.A., en este sentido se considerará como elementos relevantes la estructura reflejada en el estado de situación financiera y el estado de resultados integrales de la empresa de los periodos cerrados 2011 al 2017. Con la obtención de los resultados se realizará una proyección para los siguientes 5 periodos.

\subsection{Objetivo General}

Es presentar un análisis general de la situación financiera y económica de Filamentos Industriales S.A.

\subsection{Objetivos Específicos}

Los objetivos específicos que se desarrollaran en el presente trabajo son:

$\checkmark$ Efectuar un análisis financiero de la empresa para determinar el desempeño de sus actividades.

$\checkmark$ Efectuar un proyectado de los estados financieros para los próximos 5 años.

$\checkmark$ Realizar un diagnóstico de las implicancias de la adecuación a las Normas Internacionales de Información Financiera y evaluar su impacto en los estados financieros proyectados. 


\section{CAPÍTULO III: MARCO METODOLÓGICO}

\subsection{Metodología de recolección de la información}

$\checkmark$ Obtención de la información de los estados financieros auditados 2011

$\checkmark$ Obtención de la información de los estados financieros auditados 2012

$\checkmark$ Obtención de la información de los estados financieros auditados 2013

$\checkmark$ Obtención de la información de los estados financieros auditados 2014

$\checkmark$ Obtención de la información de los estados financieros auditados 2015

$\checkmark$ Obtención de la información de los estados financieros auditados 2016

$\checkmark \quad$ Obtención de la información de los estados financieros auditados 2017

$\checkmark \quad$ Memoria Anual de Filamentos Industriales S.A. 2011

$\checkmark \quad$ Memoria Anual de Filamentos Industriales S.A. 2012

$\checkmark \quad$ Memoria Anual de Filamentos Industriales S.A. 2013

$\checkmark \quad$ Memoria Anual de Filamentos Industriales S.A. 2014

$\checkmark$ Memoria Anual de Filamentos Industriales S.A. 2015

$\checkmark \quad$ Memoria Anual de Filamentos Industriales S.A. 2016

$\checkmark \quad$ Memoria Anual de Filamentos Industriales S.A. 2017

$\checkmark \quad$ Evaluación de la implementación de las NIIF

$\checkmark \quad$ Análisis de la proyección financiera

\subsection{Metodología de análisis de la información}

$\checkmark \quad$ Adopción de la NIIF 9

$\checkmark \quad$ Adopción de la NIIF 15

$\checkmark$ Adopción de la NIIF 16 


\section{CAPÍTULO IV: ANÁLISIS, PRESENTACIÓN Y DISCUSIÓN DE RESULTADOS}

\subsection{Análisis Financiero}

El análisis financiero de la empresa Filamentos Industriales S.A. se va a desarrollar sobre la base del estado de situación financiera y el estado de resultados integrales auditados de los periodos cerrados del año 2011 al 2017. Para ello, vamos a utilizar los métodos o técnicas para la interpretación de la situación financiera y económica de la empresa con el fin de tener un mejor entendimiento de las decisiones de financiamiento y de inversión que ha realizado la empresa y como estas decisiones han afectado a su generación de efectivo.

\subsubsection{Análisis vertical}

Para realizar el análisis vertical de la empresa, se va a tomar como base el estado de situación financiera y el estado de resultados integrales. Cada una de las cuentas que componen el estado de situación financiera (Activo, Pasivo y Patrimonio) será dividido por el total de activos; con el objetivo de determinar que porcentaje ocupa cada una de las cuentas en el estado de situación financiera con la finalidad de observar su comportamiento durante los periodos cerrados del 2011 al 2017. Las cuentas que conforman el estado de resultados integrales de la empresa, serán divididas por las ventas netas de la empresa; con el objetivo de determinar los cambios relevantes que ha tenido la empresa en el transcurso del tiempo.

(Coello Martinez, 2015) señala que:

El análisis vertical consiste en determinar la participación de cada una de las cuentas del estado financiero, con referencia sobre el total de los activos o total de los pasivos y patrimonio para el estado de situación financiera, o sobre el total de ventas para el estado de resultados. (p. VII-1) 


\subsubsection{Análisis Horizontal}

El análisis horizontal se va a realizar sobre la base del estado de situación financiera, permitiendo analizar las variaciones que se han registrado en cada una de las cuentas del estado de situación financiera de un periodo a otro, con el fin de identificar que cuentas están variando significativamente durante los periodos 2011 al 2017.

De acuerdo a lo señalado por (Coello Martinez, 2015) dispone que el análisis horizontal: "Permite comparar cuentas de estados financieros de varios periodos contables, permitiendo calificar la gestión de un periodo respecto a otro mostrando los incrementos y decrementos de las cuentas de los estados financieros comparativos". (p.VII-1).

\subsubsection{Razones o Ratios Financieros}

\subsubsection{Ratios de Liquidez}

El ratio de liquidez mide la capacidad que tiene la empresa para cubrir sus obligaciones de corto plazo en el menor tiempo posible, entre los principales ratios que vamos a analizar tenemos:

$\checkmark \quad$ Liquidez General o Razón Corriente

$\checkmark \quad$ Prueba ácida

$\checkmark \quad$ Capital de trabajo

Para realizar el análisis de los ratios de liquidez se va a tomar como base el estado de situación financiera de los periodos 2011 al 2017.

El ratio de Liquidez o Razón Corriente para (Ross, Westerfiel, Jaffe, 2012) establece que: "Una ventaja de examinar el activo y pasivo circulante es que sus valores en libros y sus valores de mercado podrían ser similares." (p.49). 
El ratio de Razón Rápida o Prueba Acida para (Ross, Westerfiel, Jaffe, 2012) precisa que "Para evaluar más afondo la liquidez, la razón rápida o prueba del ácido, se calcula del mismo modo que la rázon circulante, excepto que se omite el inventario." (p.50).

\subsubsection{Ratios de Actividad, Gestión o Rotación}

El ratio de actividad, gestión o rotación mide la eficacia en cuanto al uso de los Activos; entre los principales ratios de gestión que vamos a analizar tenemos: periodo promedio de cobro, periodo promedio de inventarios, periodo promedio de cuentas pagar entre otros. Las bases para obtener los resultados serán tomadas del estado de situación financiera y el estado de resultados integrales, con la finalidad de determinar la cantidad de días que Filamentos Industriales S.A. realiza la rotación de sus existencias, así como sus cuentas por cobrar y pagar.

\subsubsection{Ratios de Endeudamiento, Apalancamiento o solvencia}

El ratio de endeudamiento mide la capacidad de endeudamiento que tiene Filamentos Industriales S.A. frente a sus acreedores externos, la ratio de endeudamiento permite conocer la estructura de financiamiento que mantiene la empresa. Las bases sobre las cuales se obtendrán los resultados serán tomadas del estado de situación financiera entre los principales ratios que vamos a analizar tenemos:

$\checkmark$ Razón de la deuda/patrimonio o endeudamiento patrimonial, y

$\checkmark$ Razón de Patrimonio a Activo (grado de propiedad)

\subsubsection{Razones de Rentabilidad}

Este ratio mide la capacidad de la empresa para producir utilidades y mide la eficiencia de cómo la empresa utiliza sus Activos. Para determinar los resultados se va a tomar como base el estado de situación financiera y el estado de resultados integrales, entre los principales ratios a analizar tenemos:

$\checkmark$ Rentabilidad sobre las ventas (Utilidad/Ventas)

$\checkmark \quad$ Rentabilidad sobre los Activos (ROA)

$\checkmark$ Rentabilidad sobre el Patrimonio (ROE) 
Para (Ross, Westerfield, y Jaffe, 2012) considera que el "ROA es una medida de la utilidad por dólar de activos." (p.55).

(Ross, Westerfiel, Jaffe, 2012) señala que el "ROE es una herramienta que sirve para medir cómo les fue a los accionistas durante el año”. (p.55).

\subsubsection{Medidas de Desempeño.}

Son las medidas de desempeño que tiene la empresa durante un periodo determinado entre ellas tenemos:

DBITDA (Earning Before Interest, tax, depreciation and amortization); este indicador representa el resultado operativo de la empresa excluyendo todas aquellas partidas que no son salida de efectivo como por ejemplo la depreciación y la amortización.

$>$ NOPAT (Utilidad de Operación Neta después de Impuestos - UONDI); nos muestra el desempeño operativo de la empresa independientemente de su nivel de endeudamiento.

> CAPITAL DE OPERACIÓN TOTAL (COT); está conformado por la suma del capital de trabajo neto operativo más el activo fijo neto utilizable este indicador representa el valor invertido en las operaciones de la empresa.

$>$ ROIC (Rendimiento sobre el Capital Invertido); este indicador representa en cuanto está rindiendo el capital invertido en las operaciones de la empresa.

$>$ EVA (Valor Económico Agregado); nos señala si la empresa es capaz de hacer frente a sus deudas con terceros como proveedores, accionistas o tenedores de bonos con los resultados netos operativos.

WACC o CPPC (Weighted Average Cost of Capital); este ratio nos señala la capacidad que tiene la empresa de financiar sus activos con estructuras de financiamiento sea con aportes de accionistas o emisión de deuda. 


\subsection{Presentación y discusión de Resultados}

\subsubsection{Análisis Vertical}

\subsubsection{Estado de Situación Financiera}

Como se puede observar en el Anexo 1 (Análisis vertical del estado de situación financiera), la cuenta Efectivo y Equivalente de Efectivo ha mantenido un comportamiento oscilante durante los periodos 2011 al 2017. Paso de 1.12\% en el 2011 a caer en $0.44 \%$ en el 2012 , debido a que sus niveles de ventas disminuyeron en $10.82 \%$ con respecto al año anterior alcanzando un total de S/ 70,965 para el año 2012 (S/79,574 en el año 2011) ese mismo año la empresa realizo pagos de sus obligaciones financieras. Para los años 2012 y 2013 paso de $0.44 \%$ a $0.96 \%$ mejoro su posición con respecto al año 2012 debido a que la empresa realizó la venta de sus activos fijos por el importe de S/ 4 210,000. Para el año 2014, paso de $0.96 \%$ en el 2013 a caer en $0.65 \%$ para el año 2014, esta situación se dio debido a que la empresa tuvo que afrontar pagos por indemnización laborales a su personal por cierre de su planta productora; asimismo sus ventas disminuyeron en $21.02 \%$ con respecto al año anterior. Para los periodos 2014 y 2015 paso de $0.65 \%$ a caer en $0.14 \%$, está situación se originó debido a que la empresa acordó por sesión de directorio pagar dividendos a los accionistas en los meses de Julio y octubre, por el importe total de S/ 3 200,000. Para los dos últimos años 2016 y 2017 paso de $0.22 \%$ a $0.42 \%$, la empresa mejoro su posición con respecto al año anterior debido a que obtuvo préstamos bancarios que ha mejorado su flujo de caja; asimismo su nivel de ventas ha tenido un crecimiento del $15 \%$ en los dos últimos periodos.

En el rubro Cuentas por Cobrar Comerciales - Terceros, notamos que esta cuenta se ha ido incrementando durante los últimos años paso de $6.38 \%$ en el año 2011 a $9.58 \%$ en el 2013, sin embargo, en el año 2014 bajo a 9.05\% debido al cierre de su planta de producción. Con respecto a los años siguientes paso de $13 \%$ en el 2015 a $14.21 \%$ en el año 2017 debido al incremento de las ventas obteniendo un 15\% de crecimiento para los últimos dos años; este crecimiento se debe a que la empresa decidió cerrar su planta de producción del hilado polyester y reemplazarla por la importación de hilos.

Con respecto, al rubro Inmueble, Maquinaria y Equipo notamos que desde el año 2012 al 2017 los activos fijos han mostrado un descenso considerable paso de $56.31 \%$ en 
el año 2012 a $38.58 \%$ en el año 2013, debido a que Filamentos Industriales S.A. vendió sus activos fijos por un costo neto de depreciación ascendente a S/ 4 210,000 y realizó una reclasificación de sus terrenos por un importe de S/ 5 098,000 a la cuenta Inversión Inmobiliaria debido a que está siendo arrendado a su asociada. Para el periodo del 2014 descendió a $35.52 \%$ debido a que la empresa reclasifico edificios y otras construcciones, maquinaria y equipo, y equipos diversos por un importe de $S / 6434,600$ a la cuenta activos mantenidos para la venta para su posterior venta. Asimismo, en el año 2016 tuvo una disminución de $32.72 \%$ debido a que la empresa retiro de sus activos ciertos equipos de cómputo por encontrarse totalmente depreciados por un importe de S/ 978 mil.

Por el lado de los pasivos encontramos que la cuenta obligaciones financieras ha mantenido un crecimiento constante desde el año 2011 al 2017 paso de $11.26 \%$ en el 2011 a $18.89 \%$ en el 2017 , esto se originó por que la compañía obtuvo prestamos bancarias destinados para capital de trabajo e inversiones y por las letras en descuento que mantiene de sus cuentas por cobrar. 
Anexo 1: Análisis Vertical del Estado de Situación Financiera

\begin{tabular}{|c|c|c|c|c|c|c|c|c|c|c|c|c|c|c|}
\hline \multicolumn{8}{|c|}{ FILAMENTOS INDUSTRIALES S.A. } & \multicolumn{7}{|c|}{ FILAMENTOS INDUSTRIALES S.A. } \\
\hline \multicolumn{8}{|c|}{ ESTADO DE SITUACION FINANCIERA } & \multicolumn{7}{|c|}{ ANALISIS VERTICAL DEL ESTADO DE SITUACION FINANCIERA } \\
\hline & 2011 & 2012 & 2013 & 2014 & 2015 & 2016 & 2017 & 2011 & 2012 & 2013 & 2014 & 2015 & 2016 & 2017 \\
\hline \multicolumn{15}{|l|}{ Activo corriente } \\
\hline Efectivo & 1,991 & 770 & 1,309 & 837 & 182 & 300 & 566 & $1.12 \%$ & $0.44 \%$ & $0.96 \%$ & $0.65 \%$ & $0.14 \%$ & $0.22 \%$ & $0.42 \%$ \\
\hline Cuentas por Cobrar Comerciales,neto & 11,330 & 12,967 & 13,006 & 11,718 & 17,028 & 18,648 & 18,985 & $6.38 \%$ & $7.40 \%$ & $9.58 \%$ & $9.05 \%$ & $13.00 \%$ & $13.80 \%$ & $14.21 \%$ \\
\hline Cuentas por Cobrar a partes relacionada & 470 & 484 & 369 & 127 & 304 & 93 & 340 & $0.26 \%$ & $0.28 \%$ & $0.27 \%$ & $0.10 \%$ & $0.23 \%$ & $0.07 \%$ & $0.25 \%$ \\
\hline Otras Cuentas por Cobrar & 1,581 & 1,490 & 2,763 & 3,527 & 3,057 & 3,318 & 2,970 & $0.89 \%$ & $0.85 \%$ & $2.03 \%$ & $2.72 \%$ & $2.33 \%$ & $2.46 \%$ & $2.22 \%$ \\
\hline Inventarios, neto & 22,210 & 20,899 & 18,712 & 14,769 & 16,069 & 19,038 & 19,718 & $12.51 \%$ & $11.93 \%$ & $13.78 \%$ & $11.41 \%$ & $12.27 \%$ & $14.09 \%$ & $14.76 \%$ \\
\hline Gastos Pagados por Anticipado & 1,288 & 1,767 & 454 & 315 & 145 & 306 & 583 & $0.73 \%$ & $1.01 \%$ & $0.33 \%$ & $0.24 \%$ & $0.11 \%$ & $0.23 \%$ & $0.44 \%$ \\
\hline TOTAL ACTIVO CORRIENTE & $38,870.00$ & $38,377.00$ & $36,613.00$ & $31,293.00$ & $36,785.00$ & $41,703.00$ & $43,162.00$ & $21.89 \%$ & $21.91 \%$ & $26.96 \%$ & $24.17 \%$ & $28.08 \%$ & $30.86 \%$ & $32.31 \%$ \\
\hline \multicolumn{15}{|l|}{ Activo no corriente } \\
\hline Cuentas por cobrar comerciales & 1,623 & 817 & 527 & - & - & - & - & $0.91 \%$ & $0.47 \%$ & $0.39 \%$ & $0.00 \%$ & $0.00 \%$ & $0.00 \%$ & $0.00 \%$ \\
\hline Activos Mantenidos para la venta & - & - & - & 3,690 & 39 & - & - & $0.00 \%$ & $0.00 \%$ & $0.00 \%$ & $2.85 \%$ & $0.03 \%$ & $0.00 \%$ & $0.00 \%$ \\
\hline Inversión en asociada & 23,423 & 22,284 & 26,285 & 29,550 & 30,079 & 30,370 & 28,250 & $13.19 \%$ & $12.72 \%$ & $19.36 \%$ & $22.83 \%$ & $22.96 \%$ & $22.48 \%$ & $21.15 \%$ \\
\hline Inversiones Inmobiliarias, neto & 13,622 & 13,622 & 18,720 & 18,227 & 17,244 & 18,104 & 18,041 & $7.67 \%$ & $7.78 \%$ & $13.78 \%$ & $14.08 \%$ & $13.17 \%$ & $13.40 \%$ & $13.51 \%$ \\
\hline Inmueble, maquinaria y equipo & 98,700 & 98,610 & 52,391 & 45,973 & 46,225 & 44,444 & 43,703 & $55.59 \%$ & $56.31 \%$ & $38.58 \%$ & $35.52 \%$ & $35.29 \%$ & $32.89 \%$ & $32.72 \%$ \\
\hline Otros activos, neto & 1,301 & 1,422 & 1,268 & 711 & 607 & 501 & 416 & $0.73 \%$ & $0.81 \%$ & $0.93 \%$ & $0.55 \%$ & $0.46 \%$ & $0.37 \%$ & $0.31 \%$ \\
\hline TOTAL ACTIVO NO CORRIENTE & 138,669 & 136,755 & 99,191 & 98,151 & 94,194 & 93,419 & 90,410 & $78.11 \%$ & $78.09 \%$ & $73.04 \%$ & $75.83 \%$ & $71.92 \%$ & $69.14 \%$ & $67.69 \%$ \\
\hline $\begin{array}{ll}\text { TOTAL } & \text { ACTIVO }\end{array}$ & 177,539 & 175,132 & 135,804 & 129,444 & 130,979 & 135,122 & 133,572 & $100.00 \%$ & $100.00 \%$ & $100.00 \%$ & $100.00 \%$ & $100.00 \%$ & $100.00 \%$ & $100.00 \%$ \\
\hline
\end{tabular}




\begin{tabular}{|c|c|c|c|c|c|c|c|c|c|c|c|c|c|c|}
\hline \multicolumn{15}{|l|}{ Pasivo corriente } \\
\hline Obligaciones Financieras & 19,999 & 10,795 & 11,847 & 22,453 & 21,399 & 23,653 & 25,238 & $11.26 \%$ & $6.16 \%$ & $8.72 \%$ & $17.35 \%$ & $16.34 \%$ & $17.50 \%$ & $18.89 \%$ \\
\hline Cuentas por pagar comerciales & 4,709 & 13,264 & 7,479 & 1,286 & 700 & 2,673 & 634 & $2.65 \%$ & $7.57 \%$ & $5.51 \%$ & $0.99 \%$ & $0.53 \%$ & $1.98 \%$ & $0.47 \%$ \\
\hline Cuentas por pagar a partes relacionadas & 539 & 211 & 975 & 992 & 960 & 166 & 256 & $0.30 \%$ & $0.12 \%$ & $0.72 \%$ & $0.77 \%$ & $0.73 \%$ & $0.12 \%$ & $0.19 \%$ \\
\hline Otras cuentas por pagar & 2,078 & 1,690 & 1,122 & 1,388 & 1,082 & 1,139 & 832 & $1.17 \%$ & $0.96 \%$ & $0.83 \%$ & $1.07 \%$ & $0.83 \%$ & $0.84 \%$ & $0.62 \%$ \\
\hline Ingresos diferidos & - & - & - & - & 209 & 116 & 417 & $0.00 \%$ & $0.00 \%$ & $0.00 \%$ & $0.00 \%$ & $0.16 \%$ & $0.09 \%$ & $0.31 \%$ \\
\hline TOTAL PASIVO CORRIENTE & 27,325 & 25,960 & 21,423 & 26,119 & 24,350 & 27,747 & 27,377 & $15.39 \%$ & $14.82 \%$ & $15.77 \%$ & $20.18 \%$ & $18.59 \%$ & $20.53 \%$ & $20.50 \%$ \\
\hline \multicolumn{15}{|l|}{ Pasivo no corriente } \\
\hline Obligaciones financieras & 4,742 & 7,332 & 4,263 & 2,683 & 782 & - & - & $2.67 \%$ & $4.19 \%$ & $3.14 \%$ & $2.07 \%$ & $0.60 \%$ & $0.00 \%$ & $0.00 \%$ \\
\hline \multirow[t]{2}{*}{ Impuesto a la renta diferido } & 27,401 & 27,092 & 14,504 & 10,623 & 11,170 & 13,010 & 13,262 & $15.43 \%$ & $15.47 \%$ & $10.68 \%$ & $8.21 \%$ & $8.53 \%$ & $9.63 \%$ & $9.93 \%$ \\
\hline & & & & & & & & $0.00 \%$ & $0.00 \%$ & $0.00 \%$ & $0.00 \%$ & $0.00 \%$ & $0.00 \%$ & $0.00 \%$ \\
\hline TOTAL PASIVO NO CORRIENTE & 32,143 & 34,424 & 18,767 & 13,306 & 11,952 & 13,010 & 13,262 & $18.10 \%$ & $19.66 \%$ & $13.82 \%$ & $10.28 \%$ & $9.13 \%$ & $9.63 \%$ & $9.93 \%$ \\
\hline TOTAL PASIVO & 59,468 & 60,384 & 40,190 & 39,425 & 36,302 & 40,757 & 40,639 & $33.50 \%$ & $34.48 \%$ & $29.59 \%$ & $30.46 \%$ & $27.72 \%$ & $30.16 \%$ & $30.42 \%$ \\
\hline \multicolumn{15}{|l|}{ Patrimonio } \\
\hline Capital & 23,502 & 23,502 & 23,502 & 23,502 & 23,502 & 23,502 & 23,502 & $13.24 \%$ & $13.42 \%$ & $17.31 \%$ & $18.16 \%$ & $17.94 \%$ & $17.39 \%$ & $17.60 \%$ \\
\hline Acciones de inversión & 11,751 & 11,751 & 11,751 & 11,751 & 11,751 & 11,751 & 11,751 & $6.62 \%$ & $6.71 \%$ & $8.65 \%$ & $9.08 \%$ & $8.97 \%$ & $8.70 \%$ & $8.80 \%$ \\
\hline Reserva Legal & 4,924 & 4,924 & 4,924 & 4,924 & 4,924 & 4,924 & 4,924 & $2.77 \%$ & $2.81 \%$ & $3.63 \%$ & $3.80 \%$ & $3.76 \%$ & $3.64 \%$ & $3.69 \%$ \\
\hline Resultados acumulados & 77,894 & 74,571 & 55,437 & 49,842 & 54,500 & 54,188 & 52,756 & $43.87 \%$ & $42.58 \%$ & $40.82 \%$ & $38.50 \%$ & $41.61 \%$ & $40.10 \%$ & $39.50 \%$ \\
\hline PATRIMONIO & 118,071 & 114,748 & 95,614 & 90,019 & 94,677 & 94,365 & 92,933 & $66.50 \%$ & $65.52 \%$ & $70.41 \%$ & $69.54 \%$ & $72.28 \%$ & $69.84 \%$ & $69.58 \%$ \\
\hline TOTAL PASIVOS Y PATRIMONIO & 177,539 & 175,132 & 135,804 & 129,444 & 130,979 & 135,122 & 133,572 & $100.00 \%$ & $100.00 \%$ & $100.00 \%$ & $100.00 \%$ & $100.00 \%$ & $100.00 \%$ & $100.00 \%$ \\
\hline \multirow[t]{2}{*}{ Balance Check } & 0 & 0 & 0 & 0 & 0 & 0 & 0 & & & & & & & \\
\hline & 2011 & 2012 & 2013 & 2014 & 2015 & 2016 & 2017 & 2011 & 2012 & 2013 & 2014 & 2015 & 2016 & 2017 \\
\hline
\end{tabular}




\subsubsection{Estado de Resultados Integrales}

A continuación, se presenta el anexo 2 (Análisis vertical del estado de resultados integrales) notamos que el rubro de ventas netas ha descendido durante los periodos 2011 al 2015, paso de S/ 79,574 a S/ 43,241, debido a que el nivel de ventas ha ido disminuyendo en $10.82 \%$ para el año 2012, 9.1\% en el año 2013, 21.02\% en el año 2014 y $15.14 \%$ para el año 2015, debido a la fuerte competencia de hilos y telas importados de la India, debido a ello la empresa toma la decisión de cerrar su planta de producción sustituyéndola por la importación de hilos permitiéndole así competir en el mercado con productos de alta calidad similar a las que venía produciendo. Para los periodos 2016 y 2017 paso de S/ 49,726 a S/ 57,294 obteniendo un crecimiento en sus ventas del 15\%.

Los gastos de administración disminuyeron en los periodos 2011 al 2013 paso de S/ 6,373 a S/ 4,139 debido a que en el año 2011 se realizó una provisión de cobranza dudosa por S/ 810, para el año 2013, se realizó una segunda provisión de cobranza dudosa por el importe de S/787 con el fin de prever eventuales malas deudas debido a las dificultades financieras de algunos de sus clientes. En el año 2014 los gastos administrativos se incrementaron en $\mathrm{S} / 4,935$ debido al costo de indemnizaciones pagadas vinculado al cese del personal de la planta. Para los últimos 3 periodos del 2015 al 2017 paso de S/ 2,421 a S/ 2,603 este cambio se origina debido a que actualmente la empresa disminuyo su carga administrativa.

Podemos notar que el rubro Gastos Financieros hubo un incremento en los periodos 2011 al 2015 pasando de S/ 634 a S/ 1,136 debido a mayores financiamientos que la empresa ha incurrido. Para los siguientes periodos 2016 y 2017 paso de S/ 582 a S/ 513 debido a que la empresa ha ido cancelando sus obligaciones financieras. 
Anexo 2: Análisis vertical del Estado de Resultados Integrales

\begin{tabular}{|c|c|c|c|c|c|c|c|c|c|c|c|c|c|c|}
\hline \multicolumn{8}{|c|}{$\begin{array}{l}\text { FILAMENTOS INDUSTRIALES S.A. } \\
\text { ESTADO DE RESULTADOS INTEGRALES }\end{array}$} & \multicolumn{7}{|c|}{$\begin{array}{c}\text { FILAMENTOS INDUSTRIALES S.A. } \\
\text { ANÁLISIS VERTICAL DEL ESTADO DE RESULTADOS INTEGRALES }\end{array}$} \\
\hline & 2011 & 2012 & 2013 & 2014 & 2015 & 2016 & 2017 & 2011 & 2012 & 2013 & 2014 & 2015 & 2016 & 2017 \\
\hline Venta netas & 79,574 & 70,965 & 64,517 & 50,958 & 43,241 & 49,726 & 57,294 & $100.00 \%$ & $100.00 \%$ & $100.00 \%$ & $100.00 \%$ & $100.00 \%$ & $100.00 \%$ & $100.00 \%$ \\
\hline Costo de Ventas & $.71,050$ & $-66,703$ & $-60,664$ & $-53,184$ & $-39,235$ & $-44,774$ & $-51,092$ & $-89.29 \%$ & $-93.99 \%$ & $-94.03 \%$ & $-104.37 \%$ & $\begin{array}{l}-90.74 \% \\
-90.07 \%\end{array}$ & $-90.04 \%$ & $-89.18 \%$ \\
\hline UTILIDAD BRUTA & 8,524 & 4,262 & 3,853 & $-2,226$ & 4,006 & 4,952 & 6,202 & $10.71 \%$ & $6.01 \%$ & $5.97 \%$ & $-4.37 \%$ & $9.26 \%$ & $9.96 \%$ & $10.82 \%$ \\
\hline Gastos de Administración & $-6,373$ & $-5,965$ & $-4,139$ & $-4,935$ & $-2,421$ & $-2,474$ & $-2,603$ & $-8.01 \%$ & $-8.41 \%$ & $-6.42 \%$ & $-9.68 \%$ & $-5.60 \%$ & $-4.98 \%$ & $-4.54 \%$ \\
\hline Gastos de Ventas & $-1,357$ & $-1,528$ & $-1,613$ & $-1,651$ & $-1,631$ & $-1,858$ & $-1,907$ & $-1.71 \%$ & $-2.15 \%$ & $-2.50 \%$ & $-3.24 \%$ & $-3.77 \%$ & $-3.74 \%$ & $-3.33 \%$ \\
\hline Pérdida por deterioro de activos mantenidos para la venta & (1, & & $-34,972$ & $-2,200$ & - & - & - & $0.00 \%$ & $0.00 \%$ & $-54.21 \%$ & $-4.32 \%$ & $0.00 \%$ & $0.00 \%$ & $0.00 \%$ \\
\hline Otros ingresos (gastos) neto & 2,221 & 2,381 & 2,628 & $-1,930$ & 4,150 & 1,380 & 948 & $2.79 \%$ & $3.36 \%$ & $4.07 \%$ & $-3.79 \%$ & $9.60 \%$ & $2.78 \%$ & $1.65 \%$ \\
\hline UTILIDAD DE OPERACIÓN (EBIT) & 3,015 & -850 & $-34,243$ & $-12,942$ & 4,104 & 2,000 & 2,640 & $3.79 \%$ & $-1.20 \%$ & $-53.08 \%$ & $-25.40 \%$ & $9.49 \%$ & $4.02 \%$ & $4.61 \%$ \\
\hline Gastos Financieros & -634 & .964 & -915 & $-1,045$ & $-1,136$ & .582 & .513 & $-0.80 \%$ & $-1.36 \%$ & $-1.42 \%$ & $-2.05 \%$ & $-2.63 \%$ & $-1.17 \%$ & $-0.90 \%$ \\
\hline Ingresos Financieros & 305 & 259 & 192 & - & - & - & - & $0.38 \%$ & $0.36 \%$ & $0.30 \%$ & $0.00 \%$ & $0.00 \%$ & $0.00 \%$ & $0.00 \%$ \\
\hline Participación en utilidades de asociada & 3,937 & 633 & 4,393 & 4,511 & 6,054 & 4,168 & -263 & $4.95 \%$ & $0.89 \%$ & $6.81 \%$ & $8.85 \%$ & $14.00 \%$ & $8.38 \%$ & $-0.46 \%$ \\
\hline Diferencia de Cambio, Neta & -104 & 541 & .795 & - & - & -102 & 9 & $-0.13 \%$ & $0.76 \%$ & $-1.23 \%$ & $0.00 \%$ & $0.00 \%$ & $-0.21 \%$ & $0.02 \%$ \\
\hline RESULTADOS ANTES DE IMPUESTO (EBT) & 6,519 & -381 & $-31,368$ & $-9,476$ & 9,022 & 5,484 & 1,873 & $8.19 \%$ & $-0.54 \%$ & $-48.62 \%$ & $-18.60 \%$ & $20.86 \%$ & $11.03 \%$ & $3.27 \%$ \\
\hline Ingresos (Egresos) extraordinarios neto & - & - & - & - & - & - & - & $0.00 \%$ & $0.00 \%$ & $0.00 \%$ & $0.00 \%$ & $0.00 \%$ & $0.00 \%$ & $0.00 \%$ \\
\hline Impuestos & $-1,131$ & 309 & 12,588 & 3,881 & -693 & $-2,137$ & -479 & $-1.42 \%$ & $0.44 \%$ & $19.51 \%$ & $7.62 \%$ & $-1.60 \%$ & $-4.30 \%$ & $-0.84 \%$ \\
\hline UTLLIDAD NETA & 5,388 & -72 & $-18,780$ & $-5,595$ & 8,329 & 3,347 & 1,394 & $6.77 \%$ & $-0.10 \%$ & $-29.11 \%$ & $-10.98 \%$ & $19.26 \%$ & $6.73 \%$ & $2.43 \%$ \\
\hline
\end{tabular}




\subsubsection{Análisis Horizontal}

Como hemos señalado en el análisis vertical las variaciones significativas las hemos encontrado en las partidas efectivo y equivalente de efectivo, cuentas por cobrar comerciales e Inmueble maquinaria y equipos.

El Total Activo de los periodos 2012 al 2014 paso de $-1.36 \%$ a $-4.68 \%$ debido a la venta de los activos fijos de la empresa. Para los siguientes periodos 2015 al 2016 paso de $1.19 \%$ a $3.16 \%$ debido al incremento de las cuentas por cobrar comerciales, inventarios e inversión en asociadas. Finalmente, en el año 2017 descendió a -1.15\%.

Con respecto, al Total Pasivo y Patrimonio para los años 2012 al 2014 descendió de $-1.36 \%,-22.46 \%$ a $-4.68 \%$; sin embargo, en los periodos 2015 y 2016 tuvo un incremento de $1.19 \%$ y $3.16 \%$ respectivamente, pero en el periodo 2017 volvió a caer en $-1.15 \%$. Debido a que no recibió participación de utilidades en su asociada de la empresa Amcor Rigid Plastics del Perú S.A. de la cual Filamentos Industriales es propietaria de $15,437,332$ acciones comunes a un valor numeral de S/ 1.00 cada una representado el $39 \%$ del capital de dicha empresa. 
Anexo 3: Análisis Horizontal del Estado de Situación Financiera

\begin{tabular}{|c|c|c|c|c|c|c|c|c|c|c|c|c|c|}
\hline & \multicolumn{7}{|c|}{$\begin{array}{l}\text { FILAMENTOS INDUSTRIALES S.A. } \\
\text { ESTADO DE SITUACION FINANCIERA }\end{array}$} & \multicolumn{6}{|c|}{$\begin{array}{c}\text { FILAMENTOS INDUSTRIALES S.A. } \\
\text { ANALISIS HORIZONTAL DEL ESTADO DE SITUACIÓN } \\
\text { FINANCIERA }\end{array}$} \\
\hline & 2011 & 2012 & 2013 & 2014 & 2015 & 2016 & 2017 & 2012 & 2013 & 2014 & 2015 & 2016 & 2017 \\
\hline \multicolumn{14}{|l|}{ Activo corriente } \\
\hline Efectivo & 1,991 & 770 & 1,309 & 837 & 182 & 300 & 566 & $-61.33 \%$ & $70.00 \%$ & $-36.06 \%$ & $-78.26 \%$ & $64.84 \%$ & $88.67 \%$ \\
\hline Cuentas por Cobrar Comerciales, neto & 11,330 & 12,967 & 13,006 & 11,718 & 17,028 & 18,648 & 18,985 & $14.45 \%$ & $0.30 \%$ & $-9.90 \%$ & $45.31 \%$ & $9.51 \%$ & $1.81 \%$ \\
\hline Cuentas por Cobrar a partes relacionada & 470 & 484 & 369 & 127 & 304 & 93 & 340 & $2.98 \%$ & $-23.76 \%$ & $-65.58 \%$ & $139.37 \%$ & $-69.41 \%$ & $265.59 \%$ \\
\hline Otras Cuentas por Cobrar & 1,581 & 1,490 & 2,763 & 3,527 & 3,057 & 3,318 & 2,970 & $-5.76 \%$ & $85.44 \%$ & $27.65 \%$ & $-13.33 \%$ & $8.54 \%$ & $-10.49 \%$ \\
\hline Inventarios, neto & 22,210 & 20,899 & 18,712 & 14,769 & 16,069 & 19,038 & 19,718 & $-5.90 \%$ & $-10.46 \%$ & $-21.07 \%$ & $8.80 \%$ & $18.48 \%$ & $3.57 \%$ \\
\hline Gastos Pagados por Anticipado & 1,288 & 1,767 & 454 & 315 & 145 & 306 & 583 & $37.19 \%$ & $-74.31 \%$ & $-30.62 \%$ & $-53.97 \%$ & $111.03 \%$ & $90.52 \%$ \\
\hline TOTAL ACTIVO CORRIENTE & $38,870.00$ & $38,377.00$ & $36,613.00$ & $31,293.00$ & $36,785.00$ & $41,703.00$ & $43,162.00$ & $-1.27 \%$ & $-4.60 \%$ & $-14.53 \%$ & $17.55 \%$ & $13.37 \%$ & $3.50 \%$ \\
\hline \multicolumn{14}{|l|}{ Activo no corriente } \\
\hline Cuentas por cobrar comerciales & 1,623 & 817 & 527 & - & - & - & - & $-49.66 \%$ & $-35.50 \%$ & $-100.00 \%$ & $0.00 \%$ & $0.00 \%$ & $0.00 \%$ \\
\hline Activos Mantenidos para la venta & - & - & - & 3,690 & 39 & - & - & $0.00 \%$ & $0.00 \%$ & $0.00 \%$ & $-98.94 \%$ & $0.00 \%$ & $0.00 \%$ \\
\hline Inversión en asociada & 23,423 & 22,284 & 26,285 & 29,550 & 30,079 & 30,370 & 28,250 & $-4.86 \%$ & $17.95 \%$ & $12.42 \%$ & $1.79 \%$ & $0.97 \%$ & $-6.98 \%$ \\
\hline Inversiones Inmobiliarias, neto & 13,622 & 13,622 & 18,720 & 18,227 & 17,244 & 18,104 & 18,041 & $0.00 \%$ & $37.42 \%$ & $-2.63 \%$ & $-5.39 \%$ & $4.99 \%$ & $-0.35 \%$ \\
\hline Inmueble, maquinaria y equipo & 98,700 & 98,610 & 52,391 & 45,973 & 46,225 & 44,444 & 43,703 & $-0.09 \%$ & $-46.87 \%$ & $-12.25 \%$ & $0.55 \%$ & $-3.85 \%$ & $-1.67 \%$ \\
\hline Otros activos, neto & 1,301 & 1,422 & 1,268 & 711 & 607 & 501 & 416 & $9.30 \%$ & $-10.83 \%$ & $-43.93 \%$ & $-14.63 \%$ & $-17.46 \%$ & $-16.97 \%$ \\
\hline TOTAL ACTIVO NO CORRIENTE & 138,669 & 136,755 & 99,191 & 98,151 & 94,194 & 93,419 & 90,410 & $-1.38 \%$ & $-27.47 \%$ & $-1.05 \%$ & $-4.03 \%$ & $-0.82 \%$ & $-3.22 \%$ \\
\hline TOTAL ACTIVO & 177,539 & 175,132 & 135,804 & 129,444 & 130,979 & 135,122 & 133.572 & $-1.36 \%$ & $-22.46 \%$ & $-4.68 \%$ & $1.19 \%$ & $3.16 \%$ & $-1.15 \%$ \\
\hline
\end{tabular}




\begin{tabular}{|c|c|c|c|c|c|c|c|c|c|c|c|c|c|}
\hline \multicolumn{14}{|l|}{ Pasivo corriente } \\
\hline Obligaciones Financieras & 19,999 & 10,795 & 11,847 & 22,453 & 21,399 & 23,653 & 25,238 & $-46.02 \%$ & $9.75 \%$ & $89.52 \%$ & $-4.69 \%$ & $10.53 \%$ & $6.70 \%$ \\
\hline Cuentas por pagar comerciales & 4,709 & 13,264 & 7,479 & 1,286 & 700 & 2,673 & 634 & $181.67 \%$ & $-43.61 \%$ & $-82.81 \%$ & $-45.57 \%$ & $281.86 \%$ & $-76.28 \%$ \\
\hline Cuentas por pagar a partes relacionadas & 539 & 211 & 975 & 992 & 960 & 166 & 256 & $-60.85 \%$ & $362.09 \%$ & $1.74 \%$ & $-3.23 \%$ & $-82.71 \%$ & $54.22 \%$ \\
\hline Otras cuentas por pagar & 2,078 & 1,690 & 1,122 & 1,388 & 1,082 & 1,139 & 832 & $-18.67 \%$ & $-33.61 \%$ & $23.71 \%$ & $-22.05 \%$ & $5.27 \%$ & $-26.95 \%$ \\
\hline Ingresos diferidos & - & - & - & - & 209 & 116 & 417 & $0.00 \%$ & $0.00 \%$ & $0.00 \%$ & $0.00 \%$ & $-44.50 \%$ & $259.48 \%$ \\
\hline TOTAL PASIVO CORRIENTE & 27,325 & 25,960 & 21,423 & 26,119 & 24,350 & 27,747 & 27,377 & $-5.00 \%$ & $-17.48 \%$ & $21.92 \%$ & $-6.77 \%$ & $13.95 \%$ & $-1.33 \%$ \\
\hline \multicolumn{14}{|l|}{ Pasivo no corriente } \\
\hline Obligaciones financieras & 4,742 & 7,332 & 4,263 & 2,683 & 782 & - & - & $54.62 \%$ & $-41.86 \%$ & $-37.06 \%$ & $-70.85 \%$ & $0.00 \%$ & $0.00 \%$ \\
\hline Impuesto a la renta diferido & 27,401 & 27,092 & 14,504 & 10,623 & 11,170 & 13,010 & 13,262 & $-1.13 \%$ & $-46.46 \%$ & $-26.76 \%$ & $5.15 \%$ & $16.47 \%$ & $1.94 \%$ \\
\hline TOTAL PASIVO NO CORRIENTE & 32,143 & 34,424 & 18,767 & 13,306 & 11,952 & 13,010 & 13,262 & $7.10 \%$ & $-45.48 \%$ & $-29.10 \%$ & $-10.18 \%$ & $8.85 \%$ & $1.94 \%$ \\
\hline TOTAL PASIVO & 59,468 & 60,384 & 40,190 & 39,425 & 36,302 & 40,757 & 40,639 & $1.54 \%$ & $-33.44 \%$ & $-1.90 \%$ & $-7.92 \%$ & $12.27 \%$ & $-0.29 \%$ \\
\hline \multicolumn{14}{|l|}{ Patrimonio } \\
\hline Capital & 23,502 & 23,502 & 23,502 & 23,502 & 23,502 & 23,502 & 23,502 & $0.00 \%$ & $0.00 \%$ & $0.00 \%$ & $0.00 \%$ & $0.00 \%$ & $0.00 \%$ \\
\hline Acciones de inversión & 11,751 & 11,751 & 11,751 & 11,751 & 11,751 & 11,751 & 11,751 & $0.00 \%$ & $0.00 \%$ & $0.00 \%$ & $0.00 \%$ & $0.00 \%$ & $0.00 \%$ \\
\hline Reserva Legal & 4,924 & 4,924 & 4,924 & 4,924 & 4,924 & 4,924 & 4,924 & $0.00 \%$ & $0.00 \%$ & $0.00 \%$ & $0.00 \%$ & $0.00 \%$ & $0.00 \%$ \\
\hline Resultados acumulados & 77,894 & 74,571 & 55,437 & 49,842 & 54,500 & 54,188 & 52,756 & $-4.27 \%$ & $-25.66 \%$ & $-10.09 \%$ & $9.35 \%$ & $-0.57 \%$ & $-2.64 \%$ \\
\hline PATRIMONIO & 118,071 & 114,748 & 95,614 & 90,019 & 94,677 & 94,365 & 92,933 & $-2.81 \%$ & $-16.67 \%$ & $-5.85 \%$ & $5.17 \%$ & $-0.33 \%$ & $-1.52 \%$ \\
\hline TOTAL PASIVOS Y PATRIMONIO & 177,539 & 175,132 & 135,804 & 129,444 & 130,979 & 135,122 & 133,572 & $-1.36 \%$ & $-22.46 \%$ & $-4.68 \%$ & $1.19 \%$ & $3.16 \%$ & $-1.15 \%$ \\
\hline \multirow[t]{2}{*}{ Balance Check } & 0 & 0 & 0 & 0 & 0 & 0 & 0 & & & & & & \\
\hline & 2011 & 2012 & 2013 & 2014 & 2015 & 2016 & 2017 & 2012 & 2013 & 2014 & 2015 & 2016 & 2017 \\
\hline
\end{tabular}




\subsubsection{Razones o Ratios Financieros}

\subsubsection{Ratios de Liquidez}

Liquidez General: cómo podemos observar en el anexo 4 (Índices Financieros), el ratio de liquidez general o razón corriente ha mantenido un comportamiento oscilante durante los periodos 2011 al 2017. Para realizar este análisis tomaremos como base los dos últimos periodos 2016 y 2017.

El ratio de liquidez General o razón corriente del año 2016 es de 1.50 ha aumentado con respecto al 2017 que obtuvo 1.58, esto se debe a que el activo corriente es mayor al pasivo corriente a pesar que el activo corriente disminuyo en los periodos 2011 al 2015. Este ratio nos indica que la empresa está en la capacidad de cubrir sus obligaciones a corto plazo con sus activos corrientes. Por lo tanto, por cada sol que Filamentos Industriales S.A. debe estar en capacidad de pagar 1.58 de sus deudas a corto plazo.

Prueba Acida: El ratio de la prueba acida señala que la empresa solo puede pagar la octava parte de los pasivos corrientes; esto significa que la empresa no estaría en condiciones de pagar la totalidad de sus pasivos corrientes sin antes vender sus existencias.

Capital de Trabajo: realizando el análisis por los periodos 2016 de s/. 13,956 y 2017 s/. 15,785; este ratio nos lleva a concluir que la empresa está en la capacidad de pagar todos sus pasivos corrientes quedándole un disponible de caja por s/. 15,785.

\subsubsection{Ratios de Actividad, Gestión o Rotación}

Periodo Promedio de Cobro: como se puede observar en el anexo 4 (Índices Financieros), el ratio del periodo promedio de cobro de la compañía paso de 53 días en el año 2011 a 144 días en el año 2015 teniendo una disminución para el año 2017 de 121 días, este ratio establece el promedio de días el cual las cobranzas regresan con respecto a las ventas netas es decir el tiempo que se demora para convertirse en efectivo. 
Periodo Promedio de Inventarios: en el anexo 4 (Índices Financieros), podemos visualizar que el ratio de periodo promedio de inventarios se mantuvo constante durante los periodos 2011 al 2012, para los periodos siguientes tuvo un crecimiento, paso de 111 días para el año 2013 a terminar a 139 días para el año 2017; este comportamiento nos lleva a concluir que los 139 días es la rotación de inventarios que van al mercado al año, lo que demuestra que Filamentos Industriales S.A. tiene una rotación de inventarios de 3 veces por año.

Periodo Promedio de Cuentas por pagar: cómo podemos observar el periodo promedio de cuentas por pagar paso de 27 días en el año 2011 a 73 días en el año 2012, a partir del año 2013 paso de 50 días a 6 días en el 2017. Esto significa decir que Filamentos Industriales S.A. tarda en pagar a sus proveedores 6 días.

Ciclo Operativo y Conversión de Efectivo: el ciclo operativo de la empresa para el año 2017 es de 260 días, se encuentra conformado por 139 días de inventario (lo que produzco) más 121 días que le doy crédito a mis clientes (cuentas por cobrar). Sin embargo, a mis proveedores les tengo que pagar cada 6 días; por lo tanto, la conversión de efectivo de caja sería cada 254 días, el ciclo operativo es demasiado alto para Filamentos Industriales S.A. por lo que necesitaría 8 meses de financiamiento. Para cubrir el ciclo de conversión de efectivo de caja, la empresa emite letras de sus cuentas por cobrar que son descontadas por los bancos Scotiabank, Interbank, BBVA banco Continental y el banco de Crédito pagando una tasa de interés de $2.9 \%$ a $3.5 \%$.

\subsubsection{Ratios de Endeudamiento, Apalancamiento o solvencia}

Razón Deuda / Patrimonio: La relación deuda patrimonio paso de 0.43 en el 2016 a 0.44 en el 2017, este ratio nos lleva a concluir que por cada sol (S/1) que tengo en el patrimonio, Filamentos Industriales SA tiene 0.44 centavos de deuda o por cada 100 soles que tengo en el patrimonio tengo 44 soles de deuda es decir Filamento Industriales SA, con su patrimonio puede pagar su deuda total por lo tanto el patrimonio es superior a los pasivos totales. 
Grado de Propiedad: cómo podemos observar este indicador nos señala un comportamiento descendente de $69.84 \%$ en el 2016 a caer $69.58 \%$ para el 2017. Este indicador nos señala que la empresa se encuentra financiado por sus accionistas. Es decir, por cada 100 soles de financiamiento que tiene la empresa 69.58 soles está financiado por los accionistas por lo tanto no es una empresa sobre endeudada.

\subsubsection{Ratios de Crecimiento y Rentabilidad}

Margen Neto: cómo podemos observar en el anexo 4 (Índices Financieros), el margen neto no ha sido favorable para los periodos 2013 y 2014. debido a la fuerte competencia entre la producción nacional y la importación de hilos de la india; para poder afrontar esta situación la empresa tomo la decisión de cerrar su actividad de producción y sustituir sus productos de hilados por productos importados, teniendo un impacto en el margen neto de la empresa.

El margen neto para los periodos 2016 y 2017, paso de $6.73 \%$ a caer $2.43 \%$. Por lo tanto; este ratio nos lleva a concluir que por cada 100 soles que vende la empresa se está generando $2.43 \%$ de rentabilidad.

Utilidad a Activos (ROA): el ROA para el periodo 2016 es de $2.48 \%$ disminuyó con respecto al periodo 2017 de $1.04 \%$. El ROA señala que de toda la inversión realizada en mis activos totales estoy recibiendo $1.04 \%$, este ratio nos indica la eficiencia del uso de los activos por cada 100 soles que tengo invertido en los activos solamente estoy recibiendo 1.04 .

Utilidad a Patrimonio (ROE): cómo podemos analizar en el anexo 4 (Índices Financieros), el Roe no ha sido eficiente se ha visto afectado en los periodos 2012 al 2014 paso de $-0.06 \%$ a $-6.22 \%$, mejoro su posición en los años 2015 al 2017 pasando de $8.8 \%$ a $1.5 \%$. Por lo tanto, nos lleva a concluir que por cada 100 soles de patrimonio que se invierte en la empresa los accionistas están ganando $1.5 \%$ de rentabilidad. 


\subsubsection{Medidas de Desempeño}

NOPAT: como se puede observar en el anexo 4 (Índices Financieros), el Nopat del año S/ -9,059, debido a la provisión por pérdida de deterioro de los activos fijos registrados en los periodos 2013 y 2014; para los siguientes periodos 2015, 2016 y 2017, mejoro su posición paso de 2,873 a terminar en 1,861 ; esto se originó debido a que la empresa ha incrementado sus compras de mercadería pasando de S/ 36,230 a S/ 51,875 entre los periodos 2015 al 2017, teniendo como resultado el incremento del costo de ventas de la empresa afectando la utilidad operativa.

EBITDA: se determina por la utilidad operativa (EBIT) más la depreciación y la amortización realizando una comparación con respecto al año 2016 podemos observar que se ha incrementado; este indicador señala el resultado operativo del negocio es decir cuánto dinero ha ingresado a la empresa por la venta de hilos polyester. Cabe resaltar que el EBITDA no es un flujo de caja es un ingreso operativo del giro del negocio que señala cuando ha generado en dinero al año.

COT: El capital de operación total está conformado por el capital de trabajo neto operativo más el activo a largo plazo de operación, este indicador nos señala que el importe S/ 82,422 del año 2017 representa el valor invertido en las operaciones propias de la empresa; sin embargo, Filamentos Industriales S.A. tiene como Total Activo el importe de S/ 133,572, la diferencia entre el COT y el Total Activo no da como resultado el importe de S/ 51,150; está diferencia nos indica que la empresa ha invertido en otras operaciones durante los últimos años que no pertenecen al giro del negocio.

ROIC: cómo podemos observar en el anexo 4 (Índices Financieros); realizando la comparación de los años 2016 y 2017 el rendimiento sobre el capital invertido paso de $1.81 \%$ a $2.26 \%$, el ROIC representa una medida de cuanto está rindiendo el capital invertido en la empresa por lo tanto por cada 100 soles invertido en la empresa se le entrega al accionista 2.26 netos de impuestos. 
Asimismo, para determinar si la empresa está generando valor se realiza la comparación entre el ROIC y el WACC para ello tomaremos como base el año 2017. ROIC 2.26\% < WACC 24\%. Este resultado nos indica que la empresa no está generando valor porque el WACC es mayor al ROIC.

WACC: ha sido calculado sobre la base del sector en que se desarrolla la empresa en este caso es el sector textil, emitido por el mercado de capitales de la Universidad de Lima.

EVA: cómo podemos observar en la nota 4 de Índices Financieros, el comportamiento del EVA ha sido oscilante durante los periodos 2011 al 2017. Realizando la comparación de los periodos 2016 y 2017 paso de -13,717 a -18,257. Este resultado nos lleva a concluir que la empresa no está generando valor, la empresa no ha alcanzado los resultados operativos esperados a pesar del plan de adecuación que se implementó en el año 2014 para mejorar su utilidad operativa. 
Anexo 4: Índices Financieros

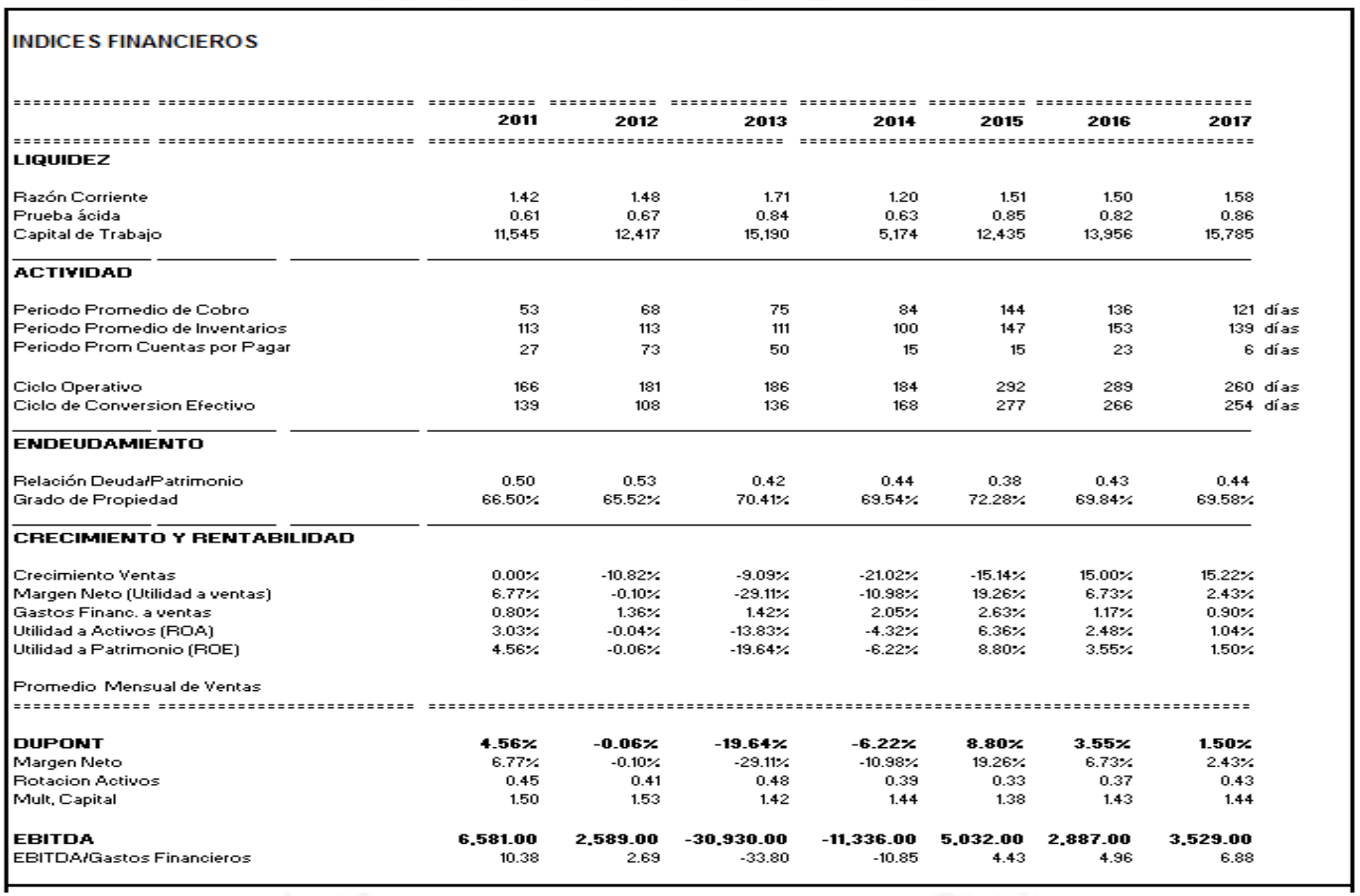




\begin{tabular}{|c|c|c|c|c|c|c|c|}
\hline \multicolumn{8}{|c|}{ 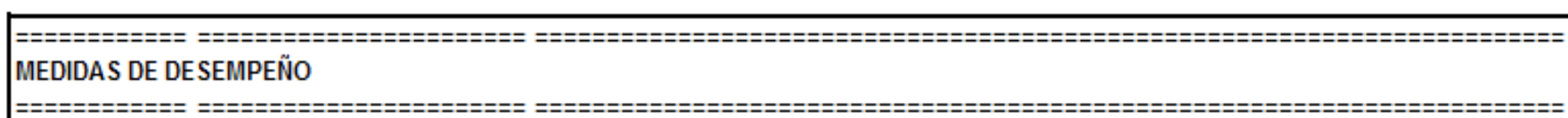 } \\
\hline & 2011 & 2012 & 2013 & 2014 & 2015 & 2016 & 2017 \\
\hline NOPATNOPAT & 2,111 & -595.00 & $-23,970$ & $-9,059$ & 2,955 & 1,440 & 1,861 \\
\hline UTILIDAD NETA & 5388 & -72 & $-18,780$ & $-5,595$ & 8,329 & 3,347 & 1,394 \\
\hline $\mathrm{FEN}=\mathrm{FCO}$ & 8,954 & 3,367 & $-15,467$ & $-3,989$ & 9,257 & 4,234 & 2,283 \\
\hline FEN/EBITDA & 1.36 & 1.30 & 0.50 & 0.35 & 1.84 & 1.47 & 0.65 \\
\hline $\mathrm{Cl}=\mathrm{COT}=\mathrm{IC}$ & 129,453 & 120,255 & 77,333 & 71,146 & 78,148 & 79,684 & 82,422 \\
\hline ACO & 36,001 & 35,120 & 33,396 & 27,451 & 33,583 & 38,079 & 39,609 \\
\hline PCO & 5,248 & 13,475 & 8,454 & 2,278 & 1,660 & 2,839 & 890 \\
\hline CTNO & 30,753 & 21,645 & 24,942 & 25,173 & 31,923 & 35,240 & 38,719 \\
\hline AFN utilizado & 98,700 & 98,610 & 52,391 & 45,973 & 46,225 & 44,444 & 43,703 \\
\hline CI/ACTIVOS TOTALES & 0.73 & 0.69 & 0.57 & 0.55 & 0.60 & 0.59 & 0.62 \\
\hline ROIC & $1.63 \%$ & $-0.49 \%$ & $-31.00 \%$ & $-12.73 \%$ & $3.78 \%$ & $1.81 \%$ & $2.26 \%$ \\
\hline WACC & $8 \%$ & $9 \%$ & $9 \%$ & $14 \%$ & $13 \%$ & $19 \%$ & $24 \%$ \\
\hline EVA & $-8,246$ & $-11,791$ & $-30,763$ & $-18,893$ & $-7,251$ & $-13,717$ & $-18,257$ \\
\hline
\end{tabular}

Fuente: Elaboración de los índices financieros del curso de Administración Financiera Prof. Roby Arbe Saldaña. 
4.3 Proyección del Estado de Situación Financiera

Anexo 5: Proyección del Estado de Situación Financiera Periodos 2018 al 2022

\begin{tabular}{|c|c|c|c|c|c|c|}
\hline \multicolumn{7}{|c|}{ Proyección del Estado de Situación Financiera } \\
\hline & BASE & 2018 & 2019 & 2020 & 2021 & 2022 \\
\hline \multicolumn{7}{|l|}{ Activo corriente } \\
\hline $\begin{array}{l}\text { Cuentas por Cobrar Comerciales, neto } \\
\text { Cuetion }\end{array}$ & $\begin{array}{l}0.26 \% \\
13.67 \%\end{array}$ & 20,443 & 22.683 & 24.923 & 27.162 & $\begin{array}{r}563 \\
29.402\end{array}$ \\
\hline Cuentas por Cobrar a partes relacionadas & $0.19 \%$ & 277 & 307 & 338 & 368 & 398 \\
\hline Otras Cuentas por Cobrar & $2.34 \%$ & 3,496 & 3,879 & 4,261 & 4,644 & 5,027 \\
\hline Inventarios, neto & $13.71 \%$ & 20,496 & 22,741 & 24,986 & 27,232 & 29,477 \\
\hline Gastos Pagados por Anticipado & $0.26 \%$ & 386 & 428 & 470 & 512 & 555 \\
\hline TOTAL ACTIVO CORRIENTE & $30.42 \%$ & 45,489 & 50,472 & 55,455 & 60,438 & 65,421 \\
\hline \multicolumn{7}{|l|}{ Activo no corriente } \\
\hline $\begin{array}{l}\text { Cuentas por cobrar comerciales } \\
\text { Activos Mantenidos para la venta }\end{array}$ & $\begin{array}{l}0.00 \% \\
0.01 \%\end{array}$ & $\overline{-}_{15}$ & - & ${ }_{18}^{-}$ & ${ }^{-} 20$ & -21 \\
\hline Inversión en asociada & $22.20 \%$ & 33,191 & 36,827 & 40,464 & 44,100 & 47,736 \\
\hline Inversiones Inmobiliarias, neto & $13.36 \%$ & 19,973 & 22,161 & 24,349 & 26,537 & 28,725 \\
\hline Inmueble, maquinaria y equipo & $33.63 \%$ & 50,294 & 55,804 & 61,313 & 66,823 & 72,333 \\
\hline Otros activos, neto & $0.38 \%$ & 571 & 634 & 696 & 759 & 821 \\
\hline TOTAL ACTIVO NO CORRIENTE & $69.58 \%$ & 104,044 & 115,442 & 126,840 & 138,238 & 149,636 \\
\hline $\begin{array}{ll}\text { TOTAL } & \text { ACTIVO } \\
\end{array}$ & $100 \%$ & 149,532 & 165,914 & 182,295 & 198,676 & 215,057 \\
\hline
\end{tabular}




\begin{tabular}{|c|c|c|c|c|c|c|}
\hline \multicolumn{7}{|l|}{ Pasivo corriente } \\
\hline Cuentas por pagar comerciales & $1.00 \%$ & 1,489 & 1,652 & 1,815 & 1,978 & 2,141 \\
\hline Cuentas por pagar a partes relacionadas & $0.35 \%$ & 522 & 579 & 636 & 694 & 751 \\
\hline Otras cuentas por pagar & $0.76 \%$ & 1,142 & 1,268 & 1,393 & 1,518 & 1,643 \\
\hline Ingresos diferidos & $0.19 \%$ & 278 & 308 & 339 & 369 & 400 \\
\hline TOTAL PASIVO CORRIENTE & $19.87 \%$ & 29,718 & 32,973 & 36,229 & 39,485 & 42,740 \\
\hline $\begin{array}{l}\text { Pasivo no corriente } \\
\text { Obligaciones financieras } \\
\text { Impuesto a la renta diferido }\end{array}$ & $\begin{array}{l}0.20 \% \\
9.36 \%\end{array}$ & $\begin{array}{r}298 \\
13,999\end{array}$ & $\begin{array}{r}330 \\
15,532\end{array}$ & $\begin{array}{r}363 \\
17,066\end{array}$ & $\begin{array}{r}395 \\
18,599\end{array}$ & $\begin{array}{r}428 \\
20,133\end{array}$ \\
\hline TOTAL PASIVO NO CORRIENTE & $9.56 \%$ & 14,296 & 15,863 & 17,429 & 18,995 & 20,561 \\
\hline TOTAL PASIVO & $29.43 \%$ & 44,014 & 48,836 & 53,658 & 58,479 & 63,301 \\
\hline \multicolumn{7}{|l|}{ Patrimonio } \\
\hline Acciones de inversión & $8.82 \%$ & 13,192 & 14,637 & 16,082 & 17,527 & 18,972 \\
\hline Reserva Legal & $3.70 \%$ & 5,528 & 6,133 & 6,739 & 7,344 & 7,950 \\
\hline Resultados acumulados & $40.40 \%$ & 60,416 & 67,034 & 73,653 & 80,271 & 86,890 \\
\hline PATRIMONIO & $70.57 \%$ & 105,518 & 117,078 & 128,637 & 140,196 & 151,756 \\
\hline TOTAL PASIVOS Y PATRIMONIO & $100 \%$ & 149,532 & 165,914 & 182,295 & 198,676 & 215,057 \\
\hline \multirow[t]{2}{*}{ Fiodance Cheost } & & $a$ & $a$ & $a$ & $a$ & $a$ \\
\hline & & 2018 & 2019 & 2020 & 2021 & 2022 \\
\hline
\end{tabular}




\subsection{Proyección del Estado de Resultados Integrales}

Anexo 6: Proyección del Estado Resultados Integrales para los Periodos 2018 al 2022.

\begin{tabular}{|c|c|c|c|c|c|c|}
\hline \multicolumn{7}{|c|}{$\begin{array}{l}\text { FILAMENTOS INDUSTRIALES S.A. } \\
\text { Provección del Estado de Resultados }\end{array}$} \\
\hline \multirow{3}{*}{$\begin{array}{l}\text { Venta de Productos } \\
\text { Costo de Ventas }\end{array}$} & BASE & 2018 & 2019 & 2020 & 2021 & 2022 \\
\hline & $\begin{array}{r}100.00 \% \\
-38.56 \%\end{array}$ & 64,140 & $\begin{array}{r}71,167 \\
-27445\end{array}$ & $\begin{array}{r}78,193 \\
-30155\end{array}$ & 85,220 & $\begin{array}{r}92,246 \\
-35,574\end{array}$ \\
\hline & $-38.56 \%$ & $-24,735$ & & & & \\
\hline UTILIDAD BRUTA & $61.44 \%$ & 39,405 & 43,721 & 48,038 & 52,355 & 56,672 \\
\hline \multirow{4}{*}{$\begin{array}{l}\text { Gastos de Administración } \\
\text { Gastos de Ventas } \\
\text { Pérdida por deterioro de activos mantenidos para la venta } \\
\text { Otros ingresos (gastos) neto }\end{array}$} & $-2.16 \%$ & $-1,385$ & $-1,537$ & $-1,689$ & $-1,840$ & $-1,992$ \\
\hline & $-1.55 \%$ & -993 & $-1,102$ & $-1,211$ & $-1,319$ & $-1,428$ \\
\hline & $0.00 \%$ & - & - & - & - & - \\
\hline & $2.00 \%$ & 1,285 & 1,426 & 1,567 & 1,708 & 1,849 \\
\hline UTILIDAD DE OPERACIÓN (EBIT) & $59.73 \%$ & 38,312 & 42,509 & 46,706 & 50,903 & 55,100 \\
\hline \multirow{4}{*}{$\begin{array}{l}\text { Gastos Financieros } \\
\text { Ingresos Financieros } \\
\text { Participación en utilidades de asociada } \\
\text { Diferencia de Cambio, Neta }\end{array}$} & $-0.67 \%$ & -430 & -477 & -524 & -571 & -618 \\
\hline & $0.00 \%$ & - & - & - & - & - \\
\hline & $3.13 \%$ & 2,009 & 2,229 & 2,449 & 2,669 & 2,889 \\
\hline & $-0.03 \%$ & -17 & -19 & -21 & -23 & -25 \\
\hline RESULTADOS ANTES DE IMPUESTO (EBT) & $62.17 \%$ & 39,873 & 44,241 & 48,609 & 52,978 & 57,346 \\
\hline \multirow{2}{*}{$\begin{array}{l}\text { Ingresos (Egresos) extraordinarios neto } \\
\text { Impuestos }\end{array}$} & $0.00 \%$ & - & - & - & - & - \\
\hline & $-0.96 \%$ & -617 & -685 & -752 & -820 & -888 \\
\hline UTILIDAD NETA & $61.20 \%$ & 39,256 & 43,557 & 47,857 & 52,157 & 56,458 \\
\hline
\end{tabular}




\subsection{Análisis de información financiera de acuerdo a NIIF.}

Filamentos Industriales S.A. para el cierre del periodo 2017 y presentación de los estados financieros no ha realizado modificaciones para la incorporación de las nuevas NIIF, que entrarán en el o después del 01 de enero del 2018 como son:

- NIIF 9 Instrumentos Financieros: presentación sobre la clasificación, medición y reconocimiento de los activos y pasivos financieros

- NIIF 15 Ingresos provenientes de contratos de clientes

- NIIF 16 Arrendamientos

La empresa considera que las normas que entraron en vigencia no son aplicables o no han tenido un impacto significativo en la presentación de los estados financieros de la empresa.

\subsubsection{NIIF 9 Instrumentos Financieros: presentación sobre la clasificación, medición y reconocimiento de los activos y pasivos financieros}

El objetivo principal de esta norma de acuerdo a lo señalado en el capitulo 1 de (IFRS, 2017) es: "El objetivo de esta norma es establecer los principios para la información financiera sobre activos y pasivos financieros, de forma que se presente información útil y relevante para los usuarios de los estados financieros para la evaluación de los importes". (p.A357).

El capítulo 4.1 de la (IFRS, 2017), dispone que:

Una entidad clasificara sus activos financieros según se midan posteriormente a costo amortizado, a valor razonable con cambios en otro resultado integral o a valor razonable con cambios en resultados sobre la base de los dos siguientes: el modelo de negocio de la entidad para gestionar los activos financieros y de las características de los flujos de efectivo contractuales del activo financiero. (p.A369)

Por lo señalado; la clasificación de los activos financieros dependerá de la manera que una entidad gestione su modelo de negocio y la existencia o no de los flujos de 
efectivo contractuales, de acuerdo a ello la entidad medirá posteriormente sus activos financieros al costo amortizado, a valor razonable con cambios en otro resultado integral o a valor razonable con cambios en resultados.

Para (Cajo y Alvarez, 2016) la clasificación dependerá de:

Si el objetivo del modelo del negocio es mantener un activo financiero con el fin de cobrar flujos de efectivo contractuales y, según las condiciones del contrato, se reciben flujos de efectivo en fechas específicas que constituyen exclusivamente a pagos del principal invertido más intereses, el activo financiero se reconocerá al costo amortizado. (pp. 579-580)

Si el modelo de negocio tiene como objetivo, tanto la obtención de flujos de efectivo contractuales como su venta y, según las condiciones del contrato, se reciben flujos de efectivo en fechas específicas que constituyen exclusivamente pagos del principal invertido más intereses sobre dicho principal, los activos financieros se valorarán a su valor razonable con cambios en el otro resultado integral (ORI). Los intereses y deterioro y diferencias en cambio se registrarán en resultados como el modelo del costo amortizado. El resto de las variaciones del valor razonable se registrarán en cuenta de patrimonio (56 resultados no realizados) y podrán reclasificarse posteriormente cuando las transacciones se realicen o se liquiden, fecha en que se cargarán o abonarán a cuentas de resultado del ejercicio (67 0 77). (pp. 579-580)

Fuera de estos escenarios, el resto de activos financieros se medirán a valor razonable con cambios en resultados a través de las cuentas 67 o 77 pérdidas y ganancias. (pp. 579580)

En cuanto a los pasivos financieros la NIIF 9 lo clasifica como pasivos financieros a valor razonable con cambios en resultados, pasivo mantenido para negociar, pasivos financieros que surjan por una transferencia de activos financieros, contratos de garantía financiera y compromisos de concesión de un préstamo.

Filamentos Industriales S.A. clasifica sus instrumentos financieros bajo la NIC 39, en la nota 2 de Principales políticas contables, inciso c) Instrumentos Financieros (Demichelli, 2017) establece: 
Los instrumentos financieros presentados en el estado de situación financiera corresponden a efectivo, cuentas por cobrar comerciales, cuentas por cobrar a partes relacionadas, otras cuentas por cobrar, obligaciones financieras, cuentas por pagar comerciales, cuentas por pagar a partes relacionadas y otras cuentas por pagar. En el momento inicial de su reconocimiento, los instrumentos financieros son medidos a su valor razonable más los costos directamente relacionados con la transacción, excepto para aquellos clasificados a su valor razonable con cambio en resultados cuyo caso los costos de transacción afectan a los resultados del ejercicio. (p.11)

A continuación, señalaremos como la empresa califica sus Activos y Pasivos financieros.

\section{a) Activos Financieros:}

Según lo señalado en las notas a los estados financieros al 31 de diciembre del 2017 y 2016 dentro de esta categoría incluye a:

Efectivo; El efectivo es un activo financiero porque representa un medio de pago y por ello es la base sobre la que se miden y reconocen todas las transacciones en los estados financieros. Los cambios realizados en el valor razonable del activo financiero son registrados en el estado de resultados integrales.

Préstamos y cuentas por cobrar; son activos financieros no derivados que dan derecho a pagos fijos o determinables y que no cotizan en un mercado activo. Surgen cuando la compañía provee dinero, bienes o servicios directamente a un deudor sin intención de negociar la cuenta por cobrar. El reconocimiento inicial de las cuentas por cobrar es a su valor nominal menos la estimación por deterioro. Las pérdidas originadas por la desvalorización son reconocidas en el estado de resultados integrales en la cuenta "Estimación para cobranza dudosa".

\section{b) Pasivos Financieros:}

Filamentos Industriales S.A. califica sus pasivos financieros en las siguientes dos categorías: a valor razonable con cambios en resultados y al costo amortizado. 
Pasivos registrados al valor razonable con cambio en resultados; al 31 de diciembre del 2017 y 2016 la empresa no tiene registrados pasivos financieros al valor razonable con cambios en resultado integral.

Pasivos registrados al costo amortizado; dentro de este rubro comprenden las obligaciones financieras, cuentas por pagar comerciales, cuentas por pagar a partes relacionadas y otras cuentas pagar; estos pasivos se reconocen al valor de transacción debido a que la empresa es parte de los acuerdos contractuales del instrumento financiero.

En la nota 2, inciso f) de deterioros de activos financieros, (Demichelli, 2017 ) dispone que: "la empresa evalúa a la fecha de cada estado de situación financiera si existe evidencia objetiva de que un activo financiero o un grupo de activos financieros se encuentran deteriorados" p.12

Asimismo, (Demichelli, 2017) establece en la nota de los estados financieros que:

Los préstamos y cuentas por cobrar que son registrados al costo amortizado, la Compañía primero evalúa individualmente si es que existe evidencia objetiva de desvalorización para activos financieros significativos, o colectivamente para activos financieros que no son individualmente significativos. Si hay evidencia objetiva de que se ha incurrido en una pérdida por desvalorización, el monto de la pérdida es cuantificado como la diferencia entre el valor del activo en libros y el valor presente de los flujos de efectivo futuros estimados descontados con la tasa de interés efectiva original del activo financiero. La Compañía considera como deteriorada las cuentas por cobrar por las cuales se ha efectuada las gestiones de cobranza sin obtener resultados favorables. (p.12)

Si el valor en libros de la cuenta por cobrar se ve afectado por la estimación de la pérdida por cobranza dudosa dicha perdida se reconoce en el estado de resultados integrales. Las cuentas por cobrar junto con la estimación asociada, serán castigadas cuando no hay evidencia de recupero de la cuenta por cobrar, si el valor estimado de la pérdida por desvalorización aumenta o disminuye debido a eventos que ocurra después de que la desvalorización es reconocida se aumenta o reduce ajustando la cuenta de 
estimación. Si el activo que fue castigado es recuperado posteriormente, dicho recupero será abonado a ingresos en el estado de resultados integrales.

Cabe resaltar, que la adopción de la NIIF 9 Instrumentos Financieros: presentación sobre la clasificación, medición y reconocimiento de los activos y pasivos financieros, no tendrá un impacto significativo para Filamentos Industriales S.A. porque la NIIF 9 evalúa la clasificación de los activos financieros sobre la base de un modelo de negocio y no por circunstancias especiales tales como la necesidad de financiamiento o por situaciones desfavorables de los activos financieros. Sin embargo, si el valor por deterioro cause un impacto negativo sobre los flujos futuros estimados del activo financiero, la cuentas por cobrar se reconocerá al costo amortizado utilizando la tasa de interés efectiva de acuerdo a lo señalado por la NIIF 9.

Por lo señalado, el riesgo de crédito individual o de grupo de las cuentas por cobrar que mantiene Filamentos Industriales S.A. se encuentra limitada debido a las políticas de créditos conservadora que establece la empresa y a la evaluación historial crediticio de sus clientes y de la condición financiera para cumplir con sus obligaciones de largo plazo. Por lo expuesto, y señalado por la empresa seguirá aplicando a los Activos y Pasivos Financieros bajo la NIC 39.

\subsubsection{NIIF 15 Ingresos provenientes de contratos de clientes.}

La NIIF 15 reemplazará a las normas de reconocimiento de ingresos como la NIC 18 Ingresos de Actividades Ordinarias y la NIC 11 Contratos de Construcción; la modificación de esta norma obedece a la introducción en el mercado de las diferentes formas de modalidades de venta que realicen las empresas sea en forma conjunta de bienes y servicios, incluyendo otros servicios accesorios como son la venta de vehículos con el servicio de mantenimiento por un año o como la venta de hilos de polyester con servicio de teñido.

El objetivo principal de esta norma de acuerdo a lo señalado por (IFRS, 2017) es: 
El objeto de esta norma es establecer los principios que aplicará una entidad para presentar información útil a los usuarios de los estados financieros sobre la naturaleza, importe, calendario e incertidumbre de los ingresos de actividades ordinarias y flujos de efectivo que surgen de un contrato con un cliente. (p.A729)

Cabe resaltar que, en le objetivo principal de la NIIF 15 es que las transacciones realizadas con terceros exige necesariamente la existencia de un contrato verbal o escrito donde se genere derechos y obligaciones exigibles tanto para la empresa como para el cliente a cambio de la entrega de bienes y servicios (obligaciones de desempeño).

El parrafo 6 de la NIIF 15 (IFRS, 2017) señala que:

Una entidad aplicará esta Norma a un contrato (distinto de un contrato enumerado en el párrafo 5) solo si la contraparte del contrato es un cliente. Un cliente es una parte que ha contratado con una entidad para obtener bienes o servicios que son resultado de las actividades ordinarias de la referida entidad a cambio de una contraprestación. (p.A730)

(Cajo y Álvarez, 2016) dispone que:

Para cumplir con las obligaciones de desempeño en un contrato se debe desarrollar los siguientes pasos o etapas: a) identificar el contrato con el cliente; b) identificar las obligaciones de desempeño; c) establecer los compromisos incluidos en el contrato; d) determinar los costos para cumplir con el contrato; e) determinar el precio de las transacción; f) distribuir el precio de la transacción entre las obligaciones del contrato; g) cumplimiento y satisfacción de las obligaciones de desempeño; h) medición del progreso. (p.327)

El Párrafo 31 de la NIIF15 señala que:

Una entidad reconocerá los ingresos de actividades ordinarias cuando (o a medida que) satisfaga un obligación de desempeño mediante la transferencia de los bienes o servicios comprometidos (es decir, uno o varios activos) al cliente. Un activo se transfiere cuando (o a medida que) el cliente obtiene el Control de se activo. (p.7) 
El párrafo 33 de la NIIF 15 establece que: el control de un activo hace referencia a la capacidad para redirigir el uso del activo y obtener sustancialmente todos sus beneficios restantes. El control incluye la capacidad de impedir que otras entidades dirijan el uso del activo y obtengan sus beneficios. Los beneficios de un activo son los flujos de efectivo potenciales (entrada o salidas de recursos) que pueden obtenerse directa o indirectamente de muchas formas:

- Utilizar el activo para producir bienes o servicios

- Usar el activo para mejorar otros activos, reducir gastos o cancelar pasivos.

- Vender el activo.

- Utilizar el activo como garantía

- Mantener el activo

De lo señalado, en la nota 2 de los estados financieros de Filamentos Industriales establece las principales políticas contables, inciso $\mathrm{m}$ ) reconocimiento de ingresos por ventas dispone que: "La empresa deberá recocer los ingresos por actividades ordinarias a medida que satisfaga las obligación de desempeño mediante la transferencia de los bienes o servicios es decir con uno o varios activos al cliente".

(Demichelli, 2017), En la nota 2 de principales políticas contables, inciso m) reconocimiento de ingresos por ventas dispone que:

La empresa reconoce la venta de bienes cuando: i) se transfieren al comprador los riesgos y beneficios importantes de la propiedad de los bienes, con independencia de la cesión o no del título legal de la propiedad; ii) la empresa no retiene ninguna clase de implicancia general, generalmente asociado con la propiedad, ni el control efectivo sobre los bienes vendidos; iii) el importe de los ingresos puede cuantificarse confiablemente; iv) es probable que los beneficios económicos relacionados con la transacción fluirán a la empresa; y v) los costos incurridos o por incurrir respecto a la transacción pueden cuantificarse confiablemente. (p.328)

Por lo señalado, Filamentos Industriales S.A. no ha adoptado NIIF 15, a la fecha reconoce los ingresos de acuerdo a lo señalado en la NIC 18; por lo tanto a modo de 
ejemplo realizaremos un caso práctico con el fin de visualizar como se aplicaría la NIIF 15 .

Caso Práctico: La empresa Calvin Klein Perú compra 30 T.M. de hilo polyester y 20 T.M. de hilo de Nylon para ser utilizado en la elaboración de prendas de vestir, además de ello establecen un contrato por el servicio de teñido que estará a cargo de Filamentos Industriales S.A. el precio estipulado por el servicio de teñido es de S/ 1,000 por T.M. dicho proceso durara 3 meses, cabe resaltar que solo se realizara el servicio de teñido a 5 T.M. del hilo polyester. Asimismo, Calvin Klein se ha hecho acreedora de un kit de tubos de repuestos como bonificación por la compra al contado, el mismo que ha sido cancelado en dos partes inicial de S/ 300,000 y el segundo pago a 30 días por S/ $316,986.60$.

Tabla 4.1

Datos del caso práctico

\begin{tabular}{|l|c|l|c|r|r|r|r|c|}
\hline \multicolumn{1}{|c|}{ Hilos } & $\begin{array}{c}\text { Precio de } \\
\text { Referencia }\end{array}$ & \multicolumn{1}{|c|}{ Condición } & $\begin{array}{c}\text { Valor de } \\
\text { venta }\end{array}$ & IGV & $\begin{array}{c}\text { Precio de } \\
\text { Venta }\end{array}$ & \% & $\begin{array}{c}\text { Precio Según } \\
\text { NIIF }\end{array}$ & $\begin{array}{c}\text { Costo de } \\
\text { Ventas }\end{array}$ \\
\hline Polyester & 304,722 & Compra & $304,722.00$ & $54,849.96$ & $359,571.96$ & $58 \%$ & $293,176.66$ & $198,336.00$ \\
\hline Nylon & 203,148 & Compra & $203,148.00$ & $36,566.64$ & $239,714.64$ & $38 \%$ & $195,451.10$ & $132,224.00$ \\
\hline $\begin{array}{l}\text { Kit de tubos de } \\
\text { repuesto }\end{array}$ & 20,000 & Bonificación & & & & $4 \%$ & $19,242.24$ & $10,000.00$ \\
\hline Servicios & 15,000 & $\begin{array}{l}\text { Pago de acuerdo a } \\
\text { servicios mensuales }\end{array}$ & $15,000.00$ & 2700 & $17,700.00$ & & $15,000.00$ & $10,500.00$ \\
\hline Totales & 542,870 & & $522,870.00$ & $94,116.60$ & $616,986.60$ & 100 & $522,870.00$ & $351,060.00$ \\
\hline
\end{tabular}


Tabla 4.2

Asientos del caso práctico

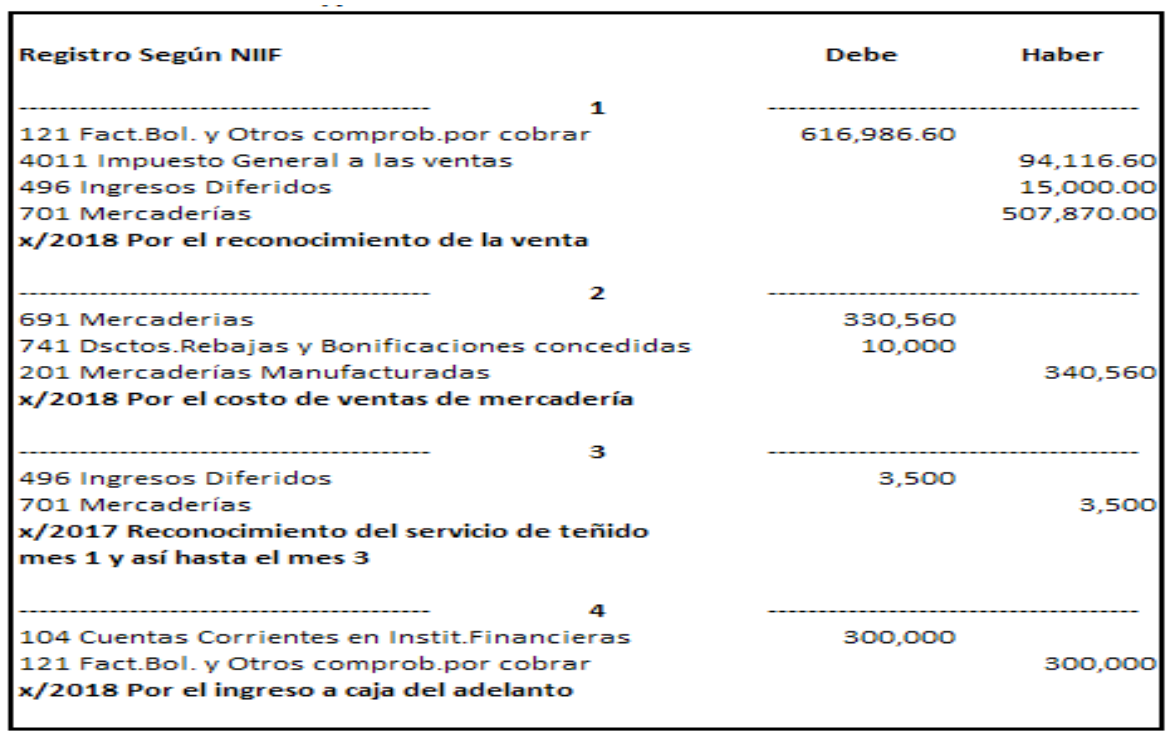

Como podemos observar en el caso de la venta de hilos, se reconoció el ingreso porque el cliente recibió a satisfacción las 50 T.M. de hilos. De acuerdo a lo señalado en el párrafo 31 de la NIIF 15 (IFRS, 2017) establece "Una entidad reconocerá los ingresos por actividades ordinarias cuando (o a medida que) satisfaga una obligación de desempeño mediante la transferencia de los bienes o servicios comprometidos (es decir, uno o varios activos) al cliente". (p.A737).

Sin embargo en el caso del servicio de teñido se difirieron los ingresos para ser reconocido mensualmente. El párrafo 39 de la NIIF 15 (IFRS, 2017) establece:

Para cada obligación de desempeño satisfecha a lo largo del tiempo de acuerdo con los párrafos 35 a 37, una entidad reconocerá los ingresos de actividades ordinarias a lo largo del tiempo midiendo el progreso hacia el cumplimiento completo de esa obligación de desempeño. El objetivo de medir el progreso es representar el desempeño de una entidad al transferir el control de los bienes o servicios comprometidos con el cliente (es decir, la satisfacción de una obligación de desempeño de una entidad). (p.A740)

Finalmente, la empresa deberá desarrollar las medidas de desempeño de acuerdo a lo establecido por la NIIF 15, como son: a) identificación del contrato con el cliente; b) identificar las obligaciones de desempeño; c) establecer los compromisos en el contrato; d) determinar los costos para cumplir con el contrato; e) determinar el precio de las transacción; f) 
distribuir el precio de la transacción entre las obligaciones del contrato; g) cumplimiento y satisfacción de las obligaciones de desempeño; h) medición del progreso, cumpliendo una de las medidas de desempeño la empresa debera cumplir con el reconocimiento de ingreso a medida que el cliente obtenga el control del activo.

\subsubsection{NIIF 16 Arrendamientos}

La NIIF 16 “Arrendamientos” entrará en vigencia en enero del 2019, está norma desarrolla un nuevo enfoque para la contabilidad del arrendatario que tendrá que reconocer activos y pasivos por derecho de uso de los activos arrendados y obligaciones creadas por los arrendamientos.

El objetivo de esta norma de acuerdo a lo señalado por la (IFRS, 2017) es: "Establecer los principios para el reconocimiento, medición, presentación e información a revelar de los arrendamientos. El objetivo es asegurar que los arrendatarios y arrendadores proporcionen información relevante de forma que represente fielmente esas transacciones". (p.A792).

La NIIF 16 señala cambios importantes para el arrendatario los arrendamientos financieros y operativos serán reemplazados por un modelo de registro único. Los arrendamientos operativos formaran parte del estado de situación financiera eliminando las diferencias entre el arrendamiento financiero y operativo se reconocerá los alquileres en el activo y pasivo por derecho de uso.

(Cajo y Álvarez, 2016), señala que la NIIF 16 trae novedades respecto al nuevo enfoque de los arrendamientos estableciendo que:

El tratamiento financiero de los arrendamientos en la contabilidad del arrendatario cambiará de forma notable. La nueva norma elimina el modelo dual de contabilidad para el arrendatario (contabilidad para arrendamiento financiero y contabilidad para el arrendamiento operativo) promoviendo un nuevo tratamiento, una sola contabilidad que se incluirá tanto en el estado de Situación Financiera (activo y pasivo por derecho de uso) 
como en el estado de resultados integral (registro de las depreciaciones, así como de los intereses implícitos). (p.239)

Para el caso del arrendador se mantendrá la práctica actual el modelo dual, es decir seguirá contabilizando los arrendamientos como financiero y operativo.

(Cajo y Álvarez, 2016), dispone que:

El derecho de uso será objeto de registro contable como un activo y a su vez las obligaciones contraídas se registrarán como un pasivo, además el activo arrendado con opción o sin opción de compra será sujeto a depreciación sistemática durante el plazo del arrendamiento. Asimismo, se reconocerá en los resultados del ejercicio, un gasto financiero por los intereses implícitos (cuenta 67) relacionados con el pago de las cantidades programadas. De esta forma, los gastos de arrendamiento lineal que antes se contabilizaba como servicios prestados por terceros (Cuenta 63) en el arrendamiento operativo se verá sustituido por un gasto por depreciación constante (cuenta 68), lo que altera el resultado final del ejercicio. (p.239)

De lo señalado, podemos concluir que la aplicación de esta norma cambiará de forma notable la contabilidad del arrendatario. Sin embargo, para Filamentos Industriales S.A. la adopción de la NIIF 16 Arrendamientos no tendrá un impacto significativo, porque la empresa no tiene contratos de arrendamientos operativos con ninguna empresa es decir no alquila bienes para el uso de sus operaciones. Cabe precisar que la nota 10 de Inversiones Inmobiliarias neto, la empresa ha suscrito un contrato de arrendamiento operativo por un inmueble de su propiedad ubicado en calle los hornos $\mathrm{N}^{\circ} 353 \mathrm{Mz}$. I Lotes $\mathrm{N}^{\circ}$ 5,6,7 y 8 de la Urbanización Infantas en el Distrito de los Olivos con un área de $15,486.8 \mathrm{~m} 2$, está operación genera ingresos mensuales por US\$ 53,000, la vigencia del contrato de alquiler será por 8 años, concluyendo el 01 de julio del 2022. Dicho inmueble se encuentra arrendado a Amcor Rigid Plastics del Perú S.A, Por lo tanto, la empresa seguirá contabilizando dicha operación como un arrendamiento operativo. 


\subsection{Aspectos Relevantes de la Reforma Tributaria}

A mediados del 2018, se publicó en el diario oficial el peruano los Decretos Legislativos $\mathrm{N}^{\circ} 1369,1422,1424$ y 1425 que desarrolla aspectos relevantes de la reforma tributaria que entrará en vigencia a partir del 01 de enero del 2019. A continuación, desarrollaremos cada uno de estos decretos y cómo afecta esta reforma a Filamentos Industriales S.A.

\subsubsection{Decreto Legislativo $\mathrm{N}^{\circ} 1369$ que modifica la Ley del Impuesto a la Renta.}

Con fecha 2 de agosto del presente año, se publicó a través del diario oficial El Peruano el Decreto Legislativo $\mathrm{N}^{\circ} 1369$ que modifica el primer y quinto párrafo del inciso i) del artículo $32^{\circ}$-A de la LIR. Asimismo, se incorporó el inciso a.4 del artículo $37^{\circ}$ de la LIR; que entrará en vigencia el 01 de enero del 2019.

El (D.L. N¹369, 2018) modifica el Articulo 32-A, disponiendo lo siguiente:

i) Servicios: Sin perjuicio de los requisitos, limitaciones y prohibiciones dispuestos por esta Ley, tratándose de servicios prestados al contribuyente por sus partes vinculadas, aquel debe cumplir el test de beneficio y proporcionar la documentación e información solicitada, como condiciones necesarias para la deducción del costo o gasto. (p.5)

La siguiente modificación del (D.L. N¹369, 2018) incorpora el inciso a.4) del Artículo $37^{\circ}$ de La LIR señalando lo siguiente:

a.4) Las regalías, y retribuciones por servicios, asistencia técnica, cesión en uso u otros de naturaleza similar a favor de beneficiarios no domiciliados, podrán deducirse como costo o gasto en el ejercicio gravable a que correspondan cuando hayan sido pagadas o acreditadas dentro del plazo establecido por el Reglamento para la presentación de la declaración jurada correspondiente a dicho ejercicio.

Los costos y gastos referidos en el párrafo anterior que no se deduzcan en el ejercicio al que correspondan serán deducibles en el ejercicio en que efectivamente se paguen, aun cuando se encuentren debidamente provisionados en un ejercicio anterior. (p.5) 
De lo señalado, en el inciso i) del artículo $32^{\circ}$-A de la LIR; se concluye que aquellos servicios prestados al contribuyente por sus partes vinculadas deberán cumplir con el test de beneficio y presentar la documentación e información para que el costo o gasto sea deducible. Sin embargo, el artículo $32^{\circ}$-A de LIR señalaba que, para estar sujeto al ámbito de aplicación el contribuyente debe realizar transacciones con sus partes vinculadas o transacciones que se realicen desde, hacia o a través de países de baja o nula imposición. De lo señalado, en la presente norma no se está considerando como gasto deducible a las transacciones realizadas con paraísos fiscales.

Con la incorporación del inciso a.4) del artículo 37 de la LIR, se está condicionando la deducción de costo o gasto de las regalías y los servicios de asistencia técnica, cesión en uso u otros de naturaleza similar realizados con contribuyentes no domiciliados; este inciso señala que será deducible en el momento de realizado el pago. Anteriormente el artículo $76^{\circ}$ de la LIR segundo párrafo establecía que los contribuyentes que contabilicen como gasto o costo las regalías, y retribuciones por los servicios de asistencia técnica, cesión en uso u otros de naturaleza similar, a favor de contribuyentes no domiciliados, dichos contribuyentes deberán abonar al fisco el monto equivalente de la retención en el mes en que en que se produzca el registro contable independiente de que si se pague o no. Con esta nueva incorporación del inciso a.4) de la LIR se elimina la obligación de pagar el importe equivalente a la retención de no domiciliado en la fecha del registro contable en su lugar condiciona la deducción de las operaciones de costo o gasto en el ejercicio en el que se pague.

Por lo señalado, con la incorporación del inciso i) en el artículo 32-A de la LIR para que Filamentos Industriales S.A. pueda deducir el costo o gasto por servicios prestados realizados con sus partes vinculadas deberá cumplir con el Test de Beneficio y documentar toda información relacionada al costo o gasto si la empresa no cumple con lo establecido en la LIR dicho costo o gasto no será deducible para determinar la base del impuesto a la renta. 


\subsubsection{Decreto Legislativo $\mathrm{N}^{\circ} 1422$ que modifica el Código Tributario.}

Este decreto modifica el artículo $16^{\circ}$ de representantes y responsables solidarios del Código Tributario destacando lo siguiente:

(D.L. $\left.\mathrm{N}^{\circ} 1422,2018\right)$ :

13. Sea sujeto de la aplicación de los párrafos segundo al quinto de la Norma XVI del Título Preliminar. La responsabilidad se atribuye a los representantes legales siempre que hayan colaborado con el diseño o la aprobación o la ejecución de actos, situaciones o relaciones económicas previstas en los párrafos segundos al quinto de la Norma XVI. (p.1)

Con la modificación incorporada en el artículo $16^{\circ}$ del Código Tributario señala que los directores o gerentes que hayan participado en el diseño o elaboración de planeamientos tributarias con la finalidad de evadir el pago de impuesto, se le imputará la figura de responsabilidad solidaria, permitiendo a la Administración Tributaria disponer de todo su patrimonio como una forma de compensación al estado.

Por lo señalado, Filamentos Industriales deberá tener en cuenta lo modificación del artículo $16^{\circ}$ del Código Tributario, para la elaboración de su planeamiento tributario ya que anteriormente la responsabilidad recaía sobre el representante legal de la empresa con esta modificación afecta a los Directores o Gerentes, teniendo la Administración Tributaria la potestad de disponer del patrimonio de los Directores o Gerentes.

\subsubsection{Decreto Legislativo $\mathrm{N}^{\circ} 1424$ que modifica la Ley del Impuesto a la Renta}

El D.L. $\mathrm{N}^{\circ} 1424$ modifica el inciso a) del artículo $37^{\circ}$ de la LIR relacionados a los gastos financieros el (D.L. $\left.\mathrm{N}^{\circ} 1424,2018\right)$ dispone lo siguiente:

a) Los intereses de deudas y los gastos originados por la constitución, renovación o cancelación de las mismas siempre que hayan sido contraídas para adquirir bienes o servicios vinculados con la obtención o producción de rentas gravadas en el país o mantener su fuente productora.

Para efecto de los gastos previstos en este inciso, se tendrá en cuenta lo siguiente: 
1. No son deducibles los intereses netos en la parte que excedan el treinta por ciento (30\%) del EBITDA del ejercicio anterior.

Para tal efecto, se entiende por: i. Interés neto: Monto de los gastos por intereses que exceda el monto de los ingresos por intereses, computables para determinar la renta neta; ii. EBITDA: Renta neta luego de efectuada la compensación de pérdidas más los intereses netos, depreciación y amortización. (p.1)

Con la modificación de esta norma se ha introducido nuevas limitaciones para la deducción de intereses, la norma señala que los intereses serán deducibles sino superan el 30\% del EBITDA (es la utilidad antes de intereses e impuestos más depreciación y amortización) de la empresa, cabe resaltar que anteriormente los intereses eran deducibles si no superaba el coeficiente de 3 sobre el patrimonio aplicable solo para partes vinculadas. Con esta modificación el límite de la deducción de gastos por intereses abarca a las partes vinculadas y no vinculadas; otra modificación que entrará en vigencia a partir del 2021 es el arrastre de pérdidas por el exceso deducible hasta cuatro ejercicios posteriores, es decir si el primer año tuve intereses que me fue imposible deducir en el periodo 1 , no lo pierdo lo puedo arrastrar es decir aplicarlo hasta 4 ejercicios posteriores.

\subsubsection{Decreto Legislativo $\mathrm{N}^{\circ} 1425$ que modifica la Ley del Impuesto a la Renta}

El D.L. $\mathrm{N}^{\circ} 1425$ incluye el concepto de devengado que anteriormente no se encontraba señalado en la LIR, por lo tanto, el (D.L. N 1425, 2018) dispone:

Se entiende que los ingresos se devengan cuando se han producido los hechos sustanciales para su generación, siempre que el derecho a obtenerlos no esté sujeto a una condición suspensiva, independientemente de la oportunidad en que se cobren y aun cuando no se hubieren fijado los términos precisos para su pago. (p.1)

De lo señalado, la Ley recoge el concepto del jurídico del devengo, los ingresos se devengan para efectos del IR cuando se han producido los hechos sustanciales para su generación independientemente de la oportunidad que se cobre o se pague. 


\section{CAPÍTULO V: CONCLUSIONES Y RECOMENDACIONES}

\subsection{Conclusiones}

- El análisis realizado a las ratios de actividad tenemos como resultado que el ciclo operativo de la empresa del año 2017 es de 260 días, este ratio se encuentra conformado por 139 días de inventario (lo que produzco) más 121 días que le doy crédito a mis clientes (cuentas por cobrar) y lo que le tengo que pagar a mis proveedores 6 días (cuentas por pagar). Por lo tanto, tenemos que la conversión de efectivo de caja sería de 254 días este ciclo de conversión de efectivo es demasiado alto para Filamentos Industriales S.A. por lo que necesitaría 8 meses de financiamiento para cubrir el ciclo de conversión de efectivo de caja. Para cubrir el ciclo de conversión de efectivo la empresa emite letras que son canjeadas con sus facturas de cuentas por cobrar que son descontadas por los bancos Scotiabank, Interbank, BBVA Banco Continental y el Banco de Crédito pagando una tasa de interés de $2.9 \%$ a $3.5 \%$.

- El resultado del cálculo del capital de operación total (COT) es por S/ 82,422 para el año 2017 este importe representa el valor invertido en las operaciones propias del giro del negocio de la empresa. Sin embargo, si comparamos con el Total Activo que tenemos en el estado de situación financiera es por S/ 133,572 la diferencia entre los dos importes da como resultado el importe de S/ 51,150 este importe señala que la empresa ha invertido en operaciones que no se encuentran relacionadas con el giro del negocio.

- El margen neto de la empresa es bajo a pesar que la empresa ha tenido en los dos últimos años un incremento del $15 \%$ en las ventas totales, esta situación nos lleva a concluir que la empresa no está gestionando bien su stock de 
inventarios, tal como se puede apreciar en la nota 23 del costo de ventas, esta nota señala que la empresa ha incrementado sus compra de mercaderías dando como resultado un incremento en el stock de los inventarios dando como resultado que el costo de ventas se ha incrementado de un año a otro.

- El cálculo de la ratio del EVA de la empresa no está generando valor eso se puede visualizar en la nota 4 de los Índices financieros de la empresa para generar valor la empresa debe dejar de invertir en otras operaciones que no son el giro de la empresa, tal como se muestra en el cálculo del capital de operaciones total (COT). La empresa debe considerar aumentar sus volúmenes de venta para mejorar sus resultados, captando a los antiguos clientes en el mercado internacional donde destinaba el $7.52 \%$ de su producción.

- La adopción de la NIIF 9 Instrumentos Financieros: presentación sobre la clasificación, medición y reconocimiento de los activos y pasivos financieros, no tendrá un impacto significativo en la elaboración de los estados financieros de la empresa debido a que la NIIF 9 evalúa la clasificación de los activos financieros sobre la base de un modelo de negocio y no por circunstancias especiales tales como la necesidad de financiamiento o por situaciones desfavorables de los activos financieros.

- La adopción de la NIIF 15 ingresos provenientes de contratos con clientes, si tendrá un impacto significativo porque la empresa actualmente reconoce el ingreso de acuerdo a lo señalado por la NIC 18; Filamentos Industriales S.A. deberá desarrollar las medidas de desempeño de acuerdo a lo establecido por la NIIF 15, como son: a) identificación del contrato con el cliente; b) identificar las obligaciones de desempeño; c) establecer los compromisos en el contrato; d) determinar los costos para cumplir con el contrato; e) determinar el precio de las transacción; f) distribuir el precio de la transacción entre las obligaciones del contrato; g) cumplimiento y satisfacción de las obligaciones de desempeño; h) medición del progreso. De acuerdo a lo señalado en el parrafo 39 de la NIIF 15 
dispone que si una de las medidas de desempeño se cumple la empresa debera reconocer el ingreso a medida que el cliente obtenga el control del activo.

- La adopción de la NIIF 16 Arrendamientos no tendrá un impacto significativo para Filamentos Industriales S.A. porque la aplicación de esta norma cambiará de forma notable la contabilidad del arrendatario. Sin embargo, para Filamentos Industriales S.A. la adopción de la NIIF 16 Arrendamientos no tendrá un impacto significativo, porque la empresa no tiene contratos de arrendamientos operativos con ninguna empresa es decir no alquila bienes para el uso de sus operaciones.

- A partir del siguiente año entra en vigencia el D.L. $\mathrm{n}^{\circ} 1425$ donde se incorpora la definición de devengado en el artículo $57^{\circ}$ de la LIR señala que: “Los ingresos se devengaran cuando se han producido los hechos sustanciales para su generación, siempre que el derecho a obtenerlos no esté sujeto a una condición suspensiva, independientemente de la oportunidad en que se cobren y aun cuando no se hubieren fijado los términos precisos para su pago". Anteriormente había mucha confusión si se debía reconocer el concepto del devengado contable o el devengado jurídico, con esta incorporación del devengado en el artículo $57^{\circ}$ de la Ley. La contraprestación o parte de esta se fije en función de un hecho o evento que se producirá en el futuro, el ingreso se devenga cuando dicho hecho o evento ocurra.

- Con lo modificación del artículo $16^{\circ}$ del Código Tributario que entrará en vigencia el 01 de enero del 2019, la empresa deberá desarrollar su planeamiento tributario en base a lo desarrollado por las normas tributarias, esta modificación da potestad a la Administración Tributarias de disponer del patrimonio de los Directores o Gerentes considerándolos como responsables solidarios. 


\subsection{Recomendaciones}

- Recomendamos que la empresa deje de invertir en operaciones que no son del giro del negocio.

- Recomendamos a la empresa incrementar su utilidad operativa para ello debe aumentar el porcentaje de ventas de la empresa, expandiéndose al mercado internacional, que desde el año 2015 no ha realizado exportaciones a sus clientes del exterior.

- Recomendamos a la empresa desarrollar las medidas de desempeño para la adopción de la NIIF 15 que tendrá un impacto significativo en el reconocimiento del ingreso de la empresa.

- Recomendamos hacer un análisis tributario para el Directorio sobre la responsabilidad solidaria de acuerdo a lo establecido en el D.L. $\mathrm{N}^{\circ} 1422$. 


\section{REFERENCIAS}

Cajo, J., \& Alvarez, J. (2016). Manual Práctico de las NIIF Tratamiento contable tributario. Lima: Instituto Pácifico.

Coello Martinez, A. M. (2015). Análisis vertical y horizontal de los estados financieros. Actualidad Empresarial, VII-1.

D.L. $N^{\circ}$ 1425. (13 de 09 de 2018). D.L. Qué modifica la LIR sobre el concepto del Devengado. EI Peruano.

D.L. N¹369. (13 de 08 de 2018). D.L. Qué modifica el artículo 32-A de la LIR. El Peruano.

D.L. N¹422. (14 de 09 de 2018). D.L. Qué modifica el Código Tributario. El Peruano.

D.L. N¹424. (13 de 09 de 2018). D.L. Qué modifica la LIR en relación a los intereses financieros. El Peruano.

Demichelli, S. \&. (2017). Estados Financieros y Dictamén de Filamentos Industriales S.A. Lima.

División de Estudios de Contadores y Empresas. (2018). Régimen Normativo 2018. Lima: Gaceta Jurídica.

FISA. (2011). Memoria Anual. Lima: Filamentos Industriles S.A.

FISA. (2014). Memoria Anual. Lima: Filamentos Industriales S.A.

FISA. (2017). Memoria Anual. Lima: Filamentos Industriales S.A.

IFRS. (2017). NORMAS NIIF (Español 2017). United Kingdon: IFRS.

Ross, Westerfiel, Jaffe. (2012). Finanzas Corportivas Novena Edición. Mexico: Mc Graw Hill Interamerican Editor. 


\section{BIBLIOGRAFÍA}

Cajo, S. J., y Álvarez, I. J. (2016). MANUAL PRÁCTICO DE LAS NIIF

TRATAMIENTO CONTABLE TRIBUTARIO. LIMA: Instituto Pacifico.

Coello Martinez, A. M. (2015). Análisis Horizontal y Vertical de los Estados Financieros. Actualidad Empresarial, VII-1.

Demichelli, S. y. (2017). Estados Financieros y Dictamén de Filamentos Industriales S.A. Lima: Grant Thornton.

División de Estudios de Contadores y Empresas. (2018). Régimen Normativo Contable 2018. Lima: Gaceta Jurídica S.A.

FILAMENTOS INDUSTRIALES S.A. (2011). Memoria Anual. LIMA: FILAMENTOS INDUSTRIALES S.A.

FILAMENTOS INDUSTRIALES S.A. (2017). Memoria Anual. LIMA: FILAMENTOS INDUSTRIALES S.A.

FILAMENTOS INDUSTRIALES SA. (2014). Memoria Anual. LIMA: FILAMENTOS INDUSTRIALES SA.

IFRS. (2017). Normas Internacionales de Información Financiera (IFRS 2017). United Kingdom: IFRS.

Ross, S., Westerfield, R., y Jaffe, J. (2012). Finanzas Corporativas Novena Edición. Mexico: McGraw Hill Interamericana Editores SA. 